\title{
A Fortune from Misfortune: Evidence from Hog Firms' Stock Price Responses to China's African Swine Fever Outbreaks
}

\author{
Tao Xiong, Wendong Zhang, Chen-Ti Chen \\ Working Paper 20-WP 602 \\ Updated August 2021 \\ Center for Agricultural and Rural Development \\ lowa State University \\ Ames, lowa 50011-1070 \\ www.card.iastate.edu
}

\begin{abstract}
Tao Xiong is Professor and Department Chair, Department of Agricultural Economics and Management, Huazhong Agricultural University, Wuhan, China 430070. E-mail: taoxiong.hzau.edu.cn.

Wendong Zhang is Associate Professor, Department of Economics, lowa State University, Ames, IA 50010. E-mail: wdzhang@iastate.edu.
\end{abstract}

Chen-Ti Chen is Postdoctoral Research Associate, Charles H. Dyson School of Applied Economics and Management and Cornell Lab of Ornithology, Cornell University, Ithaca, NY 14850. E-mail: cc2367@cornell.edu.

This publication is available online on the CARD website: www.card.iastate.edu. Permission is granted to reproduce this information with appropriate attribution to the author and the Center for Agricultural and Rural Development, lowa State University, Ames, lowa 50011-1070.

For questions or comments about the contents of this paper, please contact Wendong Zhang, wdzhang@iastate.edu.

lowa State University does not discriminate on the basis of race, color, age, ethnicity, religion, national origin, pregnancy, sexual orientation, gender identity, genetic information, sex, marital status, disability, or status as a U.S. veteran. Inquiries regarding non-discrimination policies may be directed to Office of Equal Opportunity, 3410 Beardshear Hall, 515 Morrill Road, Ames, lowa 50011, Tel. (515) 294-7612, Hotline: (515) 294-1222, email eooffice@iastate.edu. 


\title{
A Fortune from Misfortune: Evidence from Hog Firms' Stock Price Responses to China's African Swine Fever Outbreaks*
}

\author{
Tao Xiong ${ }^{\dagger} \quad$ Wendong Zhang ${ }^{\ddagger} \quad$ Chen-Ti Chen ${ }^{\S}$ \\ Forthcoming at Food Policy
}

\begin{abstract}
China is the world's largest hog producer and a leading pork importer. Since Au-gust 2018, ongoing outbreaks of African Swine Fever (ASF), a highly contagious and deadly disease affecting pigs, have hit China's livestock industries and wiped out 40\% of China's pigs. We leverage data on daily stock returns from 25 major publicly listed firms from China and eight major pork-exporting countries to provide the first sys-tematic analysis of the firm-level economic impacts of the outbreaks. We find that, on average, announcements of ASF outbreaks have led to positive and significant stock returns for both Chinese and international hog firms. China's hog firms, on average, enjoyed $10 \%$ $40 \%$ cumulative abnormal returns during the 2019 Chinese Spring Fes-tival, when investors saw signs of a near-20\% inventory loss during a peak demand season for pork. We show that larger hog firms tend to capture greater positive stock returns. Our results suggest opportunities for consolidation, expansion, and upgrades of China's meat industry that have long-run implications for its global competitiveness and efficiency.
\end{abstract}

Keywords: Stock Prices; Abnormal Returns; Agricultural Policy; Event Study; Food Security; African Swine Fever

JEL Codes: Q13, G15, Q17

${ }^{*}$ The authors gratefully acknowledge support from the USDA National Institute of Food and Agriculture Hatch Project 101,030 and grant 2019-67023-29414, the Natural Science Foundation of China Project No.71771101 and No.71873050, the Fundamental Research Funds for the Central Universities under Project No. 2662020JGPYR04, and the ISU Center for China-US Agricultural Economics and Policy, where Xiong was a visiting scholar. We also thank Nate Cook, John Crespi, Dermot Hayes, Minghao Li and Chad Hart for feedback and comments on an earlier draft.

${ }^{\dagger}$ Professor and Department Chair, Department of Agricultural Economics and Management, Huazhong Agricultural University, taoxiong@mail.hzau.edu.cn

${ }^{\ddagger}$ Associate Professor, Department of Economics and Center for Agricultural and Rural Development (CARD), Iowa State University, wdzhang@iastate.edu

${ }^{\S}$ Postdoctoral Research Associate, Charles H. Dyson School of Applied Economics and Management and Cornell Lab of Ornithology, Cornell University, cc2367@cornell.edu 


\title{
A Fortune from Misfortune: Evidence from Hog Firms' Stock Price Responses to China's African Swine Fever Outbreaks
}

\author{
August 5, 2021
}

\begin{abstract}
China is the world's largest hog producer and a leading pork importer. Since August 2018, ongoing outbreaks of African Swine Fever (ASF), a highly contagious and deadly disease affecting pigs, have hit China's livestock industries and wiped out $40 \%$ of China's pigs. We leverage data on daily stock returns from 25 major publicly listed firms from China and eight major pork-exporting countries to provide the first systematic analysis of the firm-level economic impacts of the outbreaks. We find that, on average, announcements of ASF outbreaks have led to positive and significant stock returns for both Chinese and international hog firms. China's hog firms, on average, enjoyed 10\%-40\% cumulative abnormal returns during the 2019 Chinese Spring Festival, when investors saw signs of a near-20\% inventory loss during a peak demand season for pork. We show that larger hog firms tend to capture greater positive stock returns. Our results suggest opportunities for consolidation, expansion, and upgrades of China's meat industry that have long-run implications for its global competitiveness and efficiency.
\end{abstract}

Keywords: Stock Prices; Abnormal Returns; Agricultural Policy; Event Study; Food Security; African Swine Fever

JEL Codes: Q13, G15, Q17 


\section{Introduction}

As a signature staple food, pork has critical significance for China's national security. Domestic production supplies more than 95\% of China's pork (Shao et al. 2018); however, the remaining $5 \%$ creates an annual import demand of over 2 million tons, equivalent to one-quarter of global pork exports in 2017 (USDA-FAS 2020). On August 2, 2018, China confirmed its first outbreak of African Swine Fever (ASF) (Liu et al. 2019; Mallapaty 2019; Chand 2020); and by June 5, 2020, China's Ministry of Agriculture and Rural Affairs (MARA) had reported more than 177 ASF outbreaks, which resulted in an almost 40\% reduction in hog and sow inventories - almost one-fifth of global pig inventory. Pork prices later skyrocketed, triggering public concerns about food availability and affordability (Saefong 2018). The inventory losses forced China to rely more on imports, causing major disruptions to China's food production and global protein trade patterns.

Recent projections show that ASF outbreaks will cause significant impacts on prices of major food and animal feed products, calorie availability (Mason-D'Croz et al.2020, Tian and von Cramon-Taubadel 2020), and pork exports (Carriquiry et al. 2020). However, research has yet to explore ASF's economic impacts on individual food firms. Since the fall of 2018, ASF outbreak announcements have signaled severe hog and sow inventory shortages; and, as a result, many Chinese hog firms' stock prices have risen dramatically. The resulting gain in shareholders' wealth may provide avenues for expansion and upgrade of the food industry and further transform China's food supply chain.

This study investigates the financial impacts of China's ASF outbreaks by quantifying the effects on stock returns for both Chinese and global hog firms that specialize in hog production and breeding. We use an event study approach with an autoregressive distributed lag (ARDL) specification of the market model (MM) that incorporates lagged responses of stock prices and adjusts for conditional heteroskedasticity in residuals Corhay and Rad, 1996; Coakley et al., 2008; Lee et al., 2012). We focus on the top 10 Chinese firms and 15 
leading global firms from eight major pork-exporting countries to measure, in the form of abnormal stock returns, ASF outbreaks' firm-level costs and/or benefits. In our context, abnormal stock returns are the actual stock returns and the returns that would have been realized had ASF outbreaks not taken place, which provides an unbiased estimate of the economic impact (Brown and Warner 1980). We quantify and investigate the cumulative abnormal returns (CARs) and cumulative average abnormal returns (CAARs) induced by ASF outbreaks in four distinct periods: (a) August 2018; (b) September to December 2018; (c) January to February 2019; and, (d) March to September 2019. Our study period covers, respectively, the first ASF outbreaks, its rapid spread to multiple provinces, the Spring Festival (a period of peak pork demand and one when both hog and sow inventory showed a near-20\% loss), and when China's pork prices started skyrocketing and pork imports significantly increased. We also estimate an ARDL specification of the pooled OLS regressions with lagged CARs to investigate which firm-level and socioeconomic characteristics could explain the variation of abnormal stock returns measured by CARs, and whether these relationships evolve over time.

We find that, on average, ASF announcements led to positive and significant stock returns for both Chinese and international hog firms. In particular, we find that within 15 days an ASF event announcement, Chinese hog firms, on average, enjoyed 10\%-40\% CARs during the 2019 Spring Festival. This largely reflects strong investor expectations of future meat shortage and pork price hikes in late 2019 based on February 2019 reports of a near-20\% year-over-year reduction in China's sow inventory. The magnitude of the positive CARs for international hog firms is relatively modest (1\%-10\%). We also consistently find that larger firms enjoyed greater returns across different sub-sample periods. Our study confirms at least three economic insights. First, in the early stages, the market and consumers treated ASF as a negative information shock, which was reflected in the negative stock returns in August 2018, similar to effects shown in the literature about food recalls or other animal diseases (Pozo and Schroeder 2016, Thomsen and McKenzie 2001; Jin and Kim 2008; Pendell and 
Cho 2013: Thompson et al. 2019). Second, as ASF deepened, the pork supply clearly would face significant shortages, which led to excess demand and higher stock returns and profits for hog companies. Third, as China's hog rebuilding efforts began to exceed ASF-induced inventory losses, the panic-element of the hog price and return surges became less important, and the stock returns became modest in magnitude.

The ASF outbreaks in China are arguably one of the most consequential animal disease outbreaks and our analysis has general lessons relevant to other countries. First, ASF affects many other importing countries (Korea, Vietnam, and the Philippines), and wild boars in major exporting countries (Germany and Belgium) (Bloomberg 2020; FAO 2021). Second, China's post-ASF industry consolidation and upgrade is not unique. The share of pork produced by commercial hog farms in Russia increased from $40 \%$ in 2007 to $86 \%$ in 2018 due to an ongoing ASF outbreak that started in 2007 (Ping An Securities Co. Ltd. 2019).

Our paper reveals important policy implications for Chinese and global hog industries. ASF may present long-awaited opportunities for consolidation and modernization in China's hog industry. In particular, ASF has disproportionately affected China's smaller-scale and backyard producers; thus, China's hog industry in becoming concentrated and reliant on large-scale farms (Guardian 2020, MARA 2019, 2018). This could improve both the biosecurity and efficiency of future production (Yangxiang Co. Ltd. 2020 Pig66 2019). Leveraging the positive stock returns, we also discover a speed-up of supply chain integration, with larger hog firms acquiring meat processing, pig breeding, and transportation sectors (Zhu 2019: Sina 2020a).

We contribute to the literature in two important ways. We provide the first systematic analysis of the ASF's impacts on hog industries in China and other pork-exporting countries. Our findings have global significance for the food sector, given that pork accounts for more than $60 \%$ of Chinese meat consumption and it has been difficult for China to solely rely on global pork exports to fill production gaps created by ASF. Our ex post firm-level analysis complements previous global economic models by focusing on firm-level price dynamics as 
opposed to ex ante projections relying on hypothetical scenarios based on countries or aggregated commodities, which often require strong parametrization assumptions van Tongeren et al. 2001; Liu et al. 2004).

Our study also reveals the importance of food markets' supply-side changes in explaining these hog firms' stock price responses. Previous studies find that affected firms' stock prices and returns tend to drop following both animal disease outbreaks (Jin and Kim 2008; Pendell and Cho 2013; Thompson et al. 2019) and food recalls and scandals (Thomsen and McKenzie 2001; Pozo and Schroeder 2016). Consumer responses and market demand-side factors have largely driven these drops; however, ASF is not contagious to humans (Mallapaty 2019; Chand 2020; Wang et al. 2019). Additionally, Chinese consumers have inelastic demand for meat products, and only slightly reduce pork consumption when facing price hikes (Zhang et al. 2018), which, together with the investors' expectations of drastic hog and sow inventory loss from ASF outbreaks and likely meat shortage in 2019, help explain our results.

The rest of this paper proceeds as follows. In section 2, we provide a background on the ASF outbreaks in China and relevant policies in the hog sector leading up to the outbreaks. Section 3 describes the research methodology and data. Results and policy implications follow in sections 4 and 5. Section 6 summarizes the study and discusses future research directions.

\section{Background}

ASF is a highly contagious disease that affects domesticated and wild pigs of all ages. Infected animals usually experience high fever, anorexia, lethargy, weakness, and recumbency, and most die within 10 days of infection (Spickler 2019). The ASF virus persists in distinct cycles - traditionally, the sylvatic cycle, the tick-pig cycle, the domestic (pig-pig) cycle, and the recently confirmed wild boar cycle (Beltrán-Alcrudo et al. 2017). The most commonly reported ASF outbreaks in domestic pigs is in the domestic cycle. In this cycle, the ASF virus 
may spread through direct contact via the oro-nasal route after contact with excretions from infected pigs, through the ingestion of pork or other contaminated products, or indirectly through fomites (Beltrán-Alcrudo et al. 2017). Currently, there is no approved vaccine or treatment for ASF. Pigs in Africa have been subject to the disease since the early twentieth century, and it spread to Europe in the 1950s. Eastern Europe and Russia have experienced massive economic harm due to ASF. Over 800,000 hogs died of the disease in Russia between 2007 and 2017 (Kolbasov et al. 2018).

China's first outbreak of ASF was discovered in the northeastern province of Liaoning in early August 2018. While the source is not clear, it is the same strain prevalent in Russia (Zhou et al. 2018). From August to late September of 2018, there were ASF outbreaks scattered throughout northern and central China, and eight concentrated outbreaks in Anhui Province in southern China. By late October 2018, the outbreak had reached the southwestern province of Yunnan. While, initially, all outbreaks affected smaller farms with less than 1,000 pigs, seven outbreaks in October 2018 involved producers with more than 1,000 pigs. In those seven outbreaks, the three largest producers had 19,938, 7,684, and 6,640 hogs, respectively. Outbreaks have been slowing, with more than 20 outbreaks per month in November and December of 2018 and fewer than 10 outbreaks per month in 2019. A dramatic decrease in ASF outbreaks has been observed in the first quarter of 2020 as well-through March 5, 2020, only one outbreak had been confirmed, compared to 12 outbreaks during the same period in 2019. From March 5 to April 19, 2020, however, 13 ASF outbreaks, mainly related to live pig or pork product transport, were reported nationwide, killing a total of 1,313 live pigs. In the same period last year, there were 24 outbreaks that killed 242,200 animals. According to MARA, by June 5, 2020, 177 outbreaks of ASF across 28 provinces had been confirmed, causing 20,729 confirmed infections and 14,516 pig deaths (MARA|2020).

To curb the spread of ASF, China culled millions of pigs and banned cross-province hog and pork transportation, which has significantly reduced live hog prices for producers in major pork-producing areas (Shao et al. 2018) and effectively prevented many slaughterhouses 
and meat processing factories from producing pork. The sharp decline in hog inventory follows environmental regulations that mandated a decline in livestock production, which, in its first year alone, led to a decline in hog inventory of around 20 million head in the southern provinces (Bai et al. 2018; Bai et al. 2019). 1 .

The top panel of Figure 1 shows hog inventory trends, pork imports, and prices of live pigs and pork in China since the first ASF outbreak and the bottom panel shows the number of monthly outbreaks in the same period. According to Figure 1. Chinese hog inventory decreased by 41\%, or 130 million pigs, from November 2018 to September 2019. During these 11 months, sow inventory, which determines production capacity in the next year, also decreased by $37 \%$ or 11 million sows. China's hog prices started rising in April 2019 and surged $180 \%$ over the next six months due to the severe shortage in pork supply.

An important observation from Figure 1 is that the pork price did not begin to rise in earnest until June 2019-11 months after the first outbreaks were reported. The main reason is that the contemporary pork supply, indicated by the number of slaughtered hogs, did not start to decline considerably until the third quarter of 2019. This was almost six months after the near-20\% loss in hog and sow inventory during the 2019 Spring Festival, and is consistent with hog growth cycles (Sohu 2020; Volpelli 2017). According to the data from China's National Bureau of Statistics, the quarterly percentage change (year on year) in the number of slaughtered hogs from the third quarter of 2018 to the second quarter of 2019 was only down less than $7 \%$, but significantly deteriorated to $-40 \%$ in the third quarter of $20192^{2}$ The massive drop in pork supply in the third quarter of 2019 led to the rise in pork prices in this quarter.

\footnotetext{
${ }^{1}$ In 2015, China put into effect a series of location-based environmental regulations restricting hog production, especially in the southeastern provinces, as a means to prevent and control water pollution. The regulations started with China's 13th Five-Year-Plan for Agriculture in 2015, which announced that "hog production should move away from waterways and crowded urban populations," shifting production to the west and northeast. Another related regulation divides China's provinces into the Development Control Zone and Non-development Control Zone in terms of their suitability for hog production.

${ }^{2}$ In the appendix, we present quarterly percentage changes in hog slaughter numbers and monthly percentage changes in hog and sow inventories in China for our sample period.
} 
Given that China accounts for about half of the world's pork consumption, the pork shortage also led to an urgent need to import pork from the global market. Figure 1 shows that, in comparison to August 2018, China's pork imports in 2019 surged almost 125\% in March 2019 and 170\% in May, and further reached record levels in 2020 despite the pandemic, according to the General Administration of Customs (He et al., 2020).

[Insert Figure 1: China's hog inventory, pork imports, and prices of live hog and pork (top) and ASF outbreak timeline (bottom)].

\section{Methodology and Data}

The Event Study Method. We evaluate hog firms' stock price responses to China's ASF announcements from August 2, 2018, to September 10, 2019. We combine ASF announcement records with daily stock price and stock market price index data and employ an event study approach to look for a statistically significant reaction to ASF announcements. The event study method is commonly used in the finance literature to measure a given event's economic impacts on a firm's stock or security returns (Fama et al. 1969; O'hara and Shaw 1990; Acharya 1993; Aitken and Swan 2010; Maskara and Mullineaux 2011; Black and Kim 2012; Doidge and Dyck 2015). It has also been widely applied to investigate the effects of food recalls or safety issues (Thomsen and McKenzie 2001; Salin and Hooker 2001; Lusk and Schroeder 2002; Pozo and Schroeder 2016; Moon and Tonsor 2020). The underlying assumption is that the market processes information related to events in an efficient and unbiased manner (Fama et al. 1969). An important advantage of using the event study approach is that we can construct the measurement of ASF's economic impact using stock returns observed over a short time span; whereas, the direct measurement of a firm's operating cost and productivity either requires confidential data, or may require a relatively longer time period (MacKinlay 1997). We can further use the event study approach to measure the impact of events that affect the market value of a firm, whether the events are within a firm's 
control (e.g., announcements of annual reports) or outside of its control (e.g., MARA's ASF announcements).

We divide the timeline for a specific ASF announcement into two mutually exclusive subperiods - the estimation window and event window. The estimation window consists of a period of pre-ASF-event trading days $t \in\left[T_{0}, T_{1}\right]$, where $T_{0}$ and $T_{1}$ represent the start and end times of the pre-ASF estimation window, which serves to estimate the relationship between a hog firm's stock price movement and that of the market index in the absence of an ASF event. The common practice in the literature defines the estimation window as 245 trading days immediately prior to an event, assuming those days are free of the same event. As our sample period spans August 2018 to September 2019 and includes 138 ASF events, this assumption is likely violated, as evidenced by Figure 1. Therefore, we define the estimation window as 245 trading days prior to the date a year prior to the actual ASF event date. For example, the estimation window for the ASF outbreak on June 3, 2019 is the 245 trading days from June 2, $2017\left(T_{0}\right)$ to June 2, $2018\left(T_{1}\right)$, a period that does not contain ASF events. As such, we rely on an ASF-outbreak-free period to establish baseline stock returns for a firm in the absence of ASF events and still account for the dynamics of hog production cycles (Chavas and Holt 1991) ${ }^{3}$ For each ASF event announced on the day $T_{2}$, the event window period of $t \in\left[T_{2}+1, T_{3}\right]$ starts one day after each ASF event day and consists of the following 15 trading days in our main specification (i.e., $T_{3}=T_{2}+16$ ) ${ }^{4}$ As ASF announcements could be issued at any time of the day, not just during trading times,

\footnotetext{
${ }^{3}$ Three ASF events in the last sub-period (March 2019 to September 2019) where the estimation windows still contain at least one prior outbreak remain-August 8, August 26, and September 10. When excluding these three events our results still hold, likely because there were only five outbreaks in August 2018, and the market had not started reacting to the outbreaks in the early stages.

${ }^{4}$ We select an event window with a maximum length of 15 trading days after the initial ASF announcement date in this study for two main reasons. First, the abnormal returns calculated in event studies is the difference between real stock returns and predicted stock returns estimated by a forecasting method, such as the MM or ARDL; thus, the forecasting accuracy is expected to decrease over time. In other words, the larger the event window is, the lower the forecasting accuracy would be. Second, the probability of having other non-ASF events adding noise and influencing stock price behavior is also higher with longer time periods. We also conduct an additional event study with a 20 trading day event window for the purpose of a robustness check. Generally, the results of the event study are almost consistent, regardless of specifying the length of event window as 15 or 20 trading days.
} 
the start date of the event window is set one day after the event day.

Estimating Abnormal Stock Returns. An event study approach quantifies an event's economic impact on the so-called abnormal returns through statistical regressions. We express the abnormal return for every firm $i$ as:

$$
A R_{i t}=R_{i t}-\mathrm{E}\left[R_{i t} \mid I_{t}\right]
$$

where $R_{i t}=\ln \left(\frac{P_{t}}{P_{t-1}}\right)$ is the actual stock return at date $t$, and $\mathrm{E}\left(R_{i t} \mid I_{t}\right)$ is the expected normal return conditional on information $I_{t}$, which enables us to predict the expected return if the event did not occur. Therefore, it is necessary to estimate the expected normal return in order to calculate abnormal returns. The MM is the most frequently used expected return model in practice (MacKinlay 1997) to estimate $\mathrm{E}\left(R_{i t} \mid I_{t}\right)$. The MM assumes that stock returns are a function of an overall market index and expects a deviation from this relationship in the presence of an event. In the MM, for each firm $i$, returns are given by

$$
R_{i t}=\alpha_{i}+\beta_{i} \times R_{m t}+\epsilon_{i t}, \quad \text { for all } t \in\left[T_{0}, T_{1}\right]
$$

where $R_{m t}$ is the index return of the stock market in which the firm's stocks are publicly traded at time $t ; \alpha_{i}$ and $\beta_{i}$ are parameters to be estimated; and, $\epsilon_{i}$ is the error term, which is assumed to be independent and normally distributed with zero mean.

Because of the probable serial correlation (Pozo and Schroeder 2016) and dynamic stock market performance, we use an ARDL specification of MM in our analysis. In ARDL specification of MM, for each firm $i$, returns are given by

$$
R_{i t}=\alpha_{i}+\beta_{i} \times R_{m t}+\gamma_{i} \times R_{i t-1}+\delta_{i} \times R_{m t-1}+\epsilon_{i t}, \quad \text { for all } t \in\left[T_{0}, T_{1}\right],
$$

where $R_{m t-1}$ and $R_{i t-1}$ are the index return and stock return at time $t-1$.

In addition, Giaccoto and Ali (1982) and Morgan and Morgan (1987) argue that the MM 
may mislead and the test statistic may be biased due to a violation of a strict assumption of constant coefficients and homoscedasticity of the OLS residuals in the MM. Therefore, the conditional heteroscedasticity adjusted MM is required to determine the expected returns (Bera et al. 1988), and thus, Corhay and Rad (1996), Coakley et al. (2008), and Lee et al. (2012) developed MM with generalized autoregressive conditional heteroskedasticity (GARCH). GARCH $(1,1)$ is the simplest and most robust of the family of volatility models (Bollerslev 1986; Engle 2001). Thus, the ARDL specification of MM corrected for GARCH $(1,1)$ is used as our main specification, as follows:

$$
\begin{gathered}
R_{i t}=\alpha_{i}+\beta_{i} \times R_{m t}+\gamma_{i} \times R_{i t-1}+\delta_{i} \times R_{m t-1}+\epsilon_{i t}, \quad \text { for all } t \in\left[T_{0}, T_{1}\right] \\
\epsilon_{i t} \mid \phi_{i t-1} \sim D\left(0, h_{i t}, d\right) \\
h_{i t}=\omega_{i 0}+\sum_{k=1}^{p} a_{i k} \epsilon_{i t-k}^{2}+\sum_{j=1}^{q} b_{i t} h_{i t-j}
\end{gathered}
$$

where $\phi_{i t-1}$ is a set of all available information at time $t-1$ on firm $i ; h_{i t}$ is the conditional error variance of firm $i$; $D$ is a student-t distribution with $d$ degrees of freedom; and, where $p=1$ and $q=1$.

The estimation for the GARCH $(1,1)$ model is based on a log-likelihood function. After estimating each parameter of the $\operatorname{GARCH}(1,1)$ for each firm $i$, we estimate predicted errors over the event window (i.e., 15 post-event trading days starting one day after the announcement date) by iterating the ARDL specification of MM with GARCH. The equations are as follows:

$$
E\left[R_{i t} \mid I_{t}\right]=\hat{\alpha}_{i}+\hat{\beta}_{i} \times R_{m t}+\hat{\gamma}_{i} \times R_{i t-1}+\hat{\delta}_{i} \times R_{m t-1}, \quad \text { for all } t \in\left[T_{2}+1, T_{3}\right],
$$

\footnotetext{
${ }^{5}$ The main reasons we use the GARCH $(1,1)$ specification in this study are as follows: $(a)$ the GARCH $(1,1)$ process has been fully proven as sufficient in most applications (Bollerslev 1986; Bollerslev et al. 1992, Corhay and Rad 1996); (b) the results of Ljung and Box (1978) Q test show that, under the 5\% significance level, we can not reject the null hypothesis that the residuals $\hat{\epsilon}_{t}$ from the ARDL specification of MM with GARCH $(1,1)$ are white noise and uncorrelated with the regressors; and, $(c)$ the event study results are generally consistent across different specifications of GARCH.
} 


$$
\begin{gathered}
\hat{h_{i t}}=\hat{\omega_{i 0}}+\hat{a_{i 1}} \epsilon_{i t-1}^{2}+\hat{b_{i t}} h_{i t-1}, \\
A R_{i t}=R_{i t}-\left(\hat{\alpha_{i}}+\hat{\beta}_{i} \times R_{m t}+\hat{\gamma_{i}} \times R_{i t-1}+\hat{\delta_{i}} \times R_{m t-1}\right), \quad \text { for all } t \in\left[T_{2}+1, T_{3}\right] .
\end{gathered}
$$

where $A R_{i t}$ is an abnormal return of firm $i$ estimated by the ARDL specification of MM with GARCH. This is implemented using the Stata package eventstudy2 (Kaspereit, 2015).

Cumulative Average Abnormal Returns and Hypothesis Testing. Finally, using the daily abnormal returns obtained from Equation (9), we calculate the CAARs, the mean values of $N$ ASF announcements, and our variable of interest. This requires aggregating the abnormal returns both over time and over ASF events. For firm $i$ over a time interval $\tau=\left[\tau_{1}, \tau_{2}\right]$ with $N$ ASF events, we calculate CAAR as

$$
C A A R_{i}\left(\tau_{1}, \tau_{2}\right)=\frac{1}{N} \sum_{n=1}^{N} \sum_{n=\tau_{1}}^{\tau_{2}} A R_{i t}
$$

where $T_{2}+1 \leq \tau_{1} \leq \tau_{2} \leq T_{3}$. The magnitude of $C A A R_{i}\left(\tau_{1}, \tau_{2}\right)$ reflects the impact of ASF announcements on firm $i$ 's stock returns. We focus on the sample period from August 2018 to September 2019, which covers a full year after China's first ASF outbreak. We divide the sample period into four groups: (a) August 2018, when ASF outbreaks first occurred in a small number of farms in northeastern China; (b) September 2018 to December 2018, when ASF outbreaks quickly spread to multiple provinces; (c) January 2019 to February 2019, when national leaders realized the severity of the problem due the near-20\% loss in both hog and sow inventory during the Chinese Spring Festival; and, (d) March 2019 to September 2019, when China's pork prices skyrocketed and pork imports significantly increased. The four sub-periods contain 5, 85, 11, and 37 ASF event announcements, respectively.

We also derive CARs, which we calculate as the accumulation of day-by-day abnormal returns following an ASF event obtained from Equation (9). For each ASF announcement, we calculate 15 CARs, with each measure corresponding to abnormal returns accumulated for 1 day, 2 days, and so on, up to 15 days after the announcement. While the CAAR 
provides an overall picture of ASF outbreak impacts, the CAR allows us to investigate heterogeneous effects across individual firms. Both CAR and CAAR are commonly used event-study economic variables for evaluating an event's financial effect on affected firms (Fama et al. 1969; Corrado 2011).

To determine whether the CAAR is significantly different from zero in the statistical sense, which would imply that ASF announcements do impact firms' stock returns, we conduct a hypothesis test formally stated as follows:

$$
\begin{gathered}
H_{0}: C A A R_{i}\left(\tau_{1}, \tau_{2}\right)=0 \\
H_{1}: C A A R_{i}\left(\tau_{1}, \tau_{2}\right) \neq 0 .
\end{gathered}
$$

The null hypothesis $\left(H_{0}\right)$ maintains that ASF announcements do not have a statistically significant impact on stock returns over a time interval $\tau=\left[\tau_{1}, \tau_{2}\right]$ and therefore we cannot reject that $C A A R_{i}\left(\tau_{1}, \tau_{2}\right)=0$, whereas the alternative hypothesis $\left(H_{1}\right)$ suggests the presence of abnormal returns over a time interval $\tau=\left[\tau_{1}, \tau_{2}\right]$, resulting in a non-zero $C A A R_{i}\left(\tau_{1}, \tau_{2}\right)$.

A significant clustering problem can rise when event windows of different ASF events overlap in time; and, indeed, from August 2, 2018, to September 10, 2019, MARA issued a total of 138 announcements. Thus, we employ the adjusted Boehmer et al. (1991) $t$-test (hereafter adjusted BMP $t$-test), proposed by Kolari and Pynnönen (2010), to examine the null hypothesis $\left(H_{0}\right)$ in Equation (11). This test statistic is commonly used in the literature to account for cross-correlation (Boehmer et al. 1991; Kolari and Pynnönen 2010; Pozo and Schroeder 2016). 6

Explaining Cumulative Abnormal Returns. While we do not directly test the mechanisms of the effect of ASF announcements on stock returns, we do examine whether and how the ASF announcement details and firm characteristics explain the abnormal stock returns. We use CAR as the outcome variable of interest, and focus on the CAR values that

\footnotetext{
${ }^{6}$ The derivation of the adjusted BMP $t$-test is presented in the online appendix.
} 
accumulate abnormal returns over 15 days after the outbreak.

A common approach in the literature uses the cross-sectional ordinary least squares (OLS) model, exploiting the cross-event variation in the event and firm characteristics to estimate the coefficients of interest (Savor 2012). An alternative approach pools together CAR observations for each event on each day over the event window to construct panel data and estimate a pooled OLS model-researchers argue that such long-horizon regressions capture more information and produce more precise results (Fama and French 1988; Hjalmarsson 2011; Pozo and Schroeder 2016). However, this type of dependent variable by construction contains dynamic information. As such, we extend the literature to estimate a generalized ARDL model following a specification similar to that of Equation (3). The difference between this model and that in Equtaion (3) is that the data here features a panel of firm-event-specific CAR values over the 15-day estimation window, rather than a time series data of stock returns from the 245 pre-ASF trading days.

For each ASF event $j$ and each firm $i$, and $t$ days after an ASF event where $t \in[1,15]$, we estimate the following regression model:

$$
C A R_{j i t}=\alpha+\beta C A R_{j i, t-1}+\boldsymbol{X}_{j i t}^{\prime} \boldsymbol{\gamma}+\boldsymbol{X}_{j i, t-1}^{\prime} \boldsymbol{\delta}+\boldsymbol{Z}_{j i}^{\prime} \boldsymbol{\phi}+\varepsilon_{j i t}
$$

where $C A R$ is the rolling sum of abnormal returns after each ASF announcement, and $\boldsymbol{X}$ and $\boldsymbol{Z}$ are vectors of time-varying and time-invariant variables, respectively. For both Chinese and foreign firms, we estimate an $\operatorname{ARDL}(1,1, k)$ model in Equation (12) separately for each of the four sub-periods, as well as for the full sample, where only one lag of $C A R$ and $\boldsymbol{X}$ are included in the regression, and $k$ is the number of time-varying variables $]^{7}$ We describe each variable included in the regression as follows. For Chinese hog firms, $\boldsymbol{X}$ includes: $(a)$ daily trading volume that captures the firm size and capacity, which is measured by the

\footnotetext{
${ }^{7}$ We include only one lag of the variables because we have a short time-series panel data with only 15 periods. The regression results from the $\operatorname{ARDL}(2,2, k)$ specification are consistent, although we lose degree of freedom in the case.
} 
percentage of outstanding shares traded for that day; $(b)$ the daily number of searches for "African Swine Fever" on Baidu, which measures the general interest or concerns among the public regarding ASF 8 and, $(c)$ Chinese daily feeder pig prices, which we use as the proxy for the production costs for all Chinese hog producing firms. $\boldsymbol{Z}$ includes: $(a)$ annual hog breeding and producing income share of total firm income in 2017, which accounts for differential impacts on CAR if a firm is also engaged in business other than hog producing and breeding; (b) a binary indicator common to all firms that equals 1 if the ASF outbreak occurred in a large-scale (at least 500 pigs) pig farm; $(c)$ the number of infected pigs reported from the ASF announcement; and, $(d)$ a binary indicator that equals 1 if the firm has at least one hog facility in a single county that reported an ASF outbreak, which captures the disproportionate impacts on a firm when its facilities are subject to greater risk from being closer to the contaminated hog farm.

For foreign hog firms, time-varying variables include: $(a)$ daily trading volume, defined the same as above; and, $(b)$ the daily number of "African Swine Fever" searches on Google. Time-invariant variables include: $(a)$ the number of infected pigs reported from the ASF announcement; and, $(b)$ differential trading costs from these food exporters to China, commonly included in gravity models of trade, by using a country-specific trade cost measure (Novy 2013). Some independent variables included in the Chinese hog firm regression are dropped here because none of the 15 foreign hog firms have facilities in infected Chinese counties.

For all regressions, we include day-since-announcement dummy variables to flexibly account for day-by-day unobserved shocks common to all ASF events. We further include month and year dummy variables in the full sample regressions to capture general macroeconomic and commodity fluctuations that contribute to the firms' stock returns. We estimate Equation (12) using the pooled OLS estimator. Although we have a rather short time-series for our panel data, we use cluster-robust standard errors to account for potential serial

\footnotetext{
${ }^{8}$ Google is prohibited in China. Baidu is one of the most commonly used search engines in China.
} 
correlation within the event window for each ASF outbreak.

Data Sources. Our analysis relies on two main data sources-ASF announcements and stock prices. We collect ASF announcement data from China's MARA homepage. Following each ASF outbreak, MARA announces the county-level location and specific site (i.e., pig farm, slaughterhouse, or transport vehicle) of event detection, the number of hogs in inventory, and the number of infected and dead pigs. MARA issued a total of 138 ASF announcements during our study period (MARA 2020). We collect daily stock price data from Yahoo Finance. Of those listed on stock markets, we select China's top 10 hog firms and 15 global hog firms from eight countries that export pork to China.$^{910}$ Of these, with China excluded, the remaining eight pork-exporting countries represented $32 \%$ of global pork exports in 2018 ${ }^{11}$ For each hog firm, we collect the stock price index for the market in which the firm's stocks are traded, its headquarters' location, and the locations of all its hog facilities to determine whether a particular ASF outbreak affects the firm. The daily feeder pig prices are collected from the Chinese Association of Animal Agriculture. The hog breeding and producing income share data are collected from the hog firms' 2017 annual reports, the latest report before the first ASF outbreak.

\section{Results}

Descriptive Results. ASF outbreaks have had a dramatic impact on China's hog and pork markets, as well as global food trade. As discussed earlier, Figure 1, shows China's hog inventory decreased by more than $40 \%$ from the end of 2018 to September 2019, which drove up both hog and pork prices and the demand for pork imports. Specifically, hog and

\footnotetext{
${ }^{9}$ See Appendix Table A.4 for the complete list of the Chinese and global hog firms included in the analysis.

${ }^{10}$ Our analysis pertains to the publicly-traded hog firms that specialize in raising and breeding pigs, rather than hog processors or pork processors. Considering that hog producers are also associated with small- or medium-scale hog farmers, we use the term "hog firms" throughout the paper.

${ }^{11}$ Based on authors' own calculation using data from the United Nations Commodity Trade Statistics Database (Standard International Trade Classification: Meat of swine, fresh, chilled or frozen).
} 
pork prices both rose by more than $20 \mathrm{CNY} / \mathrm{kg}$ one year after the first ASF outbreak.

Figure 2 uses boxplots to show descriptively how the decline in China's hog inventory and the associated increase in imported meat demand translated into an upswing in Chinese and foreign hog firms' stock prices. Using the stock prices of August 1, 2018, as a benchmark, Figure 2 presents stock price trajectories from August 2018 to September 2019 for the 10 largest Chinese hog firms in the top panel and 15 major foreign hog firms in the bottom panel. We include composite stock market changes over the same time to illustrate the magnitude of stock price movements for these food firms relative to the general market.

Figure 2 shows that Chinese hog firms' stock prices experienced a slight decline immediately after the first ASF announcement in 2018, then increased dramatically the following year. We note that the magnitude of the daily stock price increase among the 10 Chinese hog firms greatly exceeds the increases in the pork and pig prices presented in Figure 1. Specifically, when compared to the August 2018 baseline, Figure 2 shows a 50\%-300\% rise in stock prices starting in February 2019, during which the Chinese Spring Festival, a peak demand season for pork, took place. In contrast, overall stock market trends only show a modest increase during the same period. The dramatic rise might reflect investors' expectations of a severe pork shortage. On the other hand, global hog firms' stock prices, shown in the bottom panel of Figure 2, also experienced substantial and consistent increases, but of a smaller magnitude than Chinese hog firms. The firm-level stock price hikes for global hog firms mainly reflect the boost in China's imported pork demand, and they are significantly greater than the general market movements for the United States and Europe, but not much larger than those for Brazil. This is in part because Brazil's stock market experienced much stronger surges from China's elevated demand for Brazilian soybeans to cope with the U.S.-China trade war.

[Insert Figure 2: Stock price changes for Chinese and global hog firms following China's ASF outbreak.] 
Event Study Results for Chinese Hog Firms. While Figure 2 provides suggestive evidence of positive financial impacts for hog firms, it could be biased, as it ignores the fluctuations and seasonality of hog firms' stock price changes even in the absence of ASF outbreaks. The event study approach allows us to isolate ASF outbreak effects in the form of abnormal stock returns ${ }^{12}$ Figure 3 plots the estimated CAARs for Chinese hog firms from the event study method. We find that CAARs for Chinese hog firms exhibited different patterns as ASF triggered market concerns about the pork supply and shortages-immediately after each ASF announcement, the average Chinese hog firm saw a negative CAAR over a seven-day period in August 2018, which is similar to the adverse stock movements commonly observed following a food recall or food safety event (Thomsen and McKenzie 2001; Pozo and

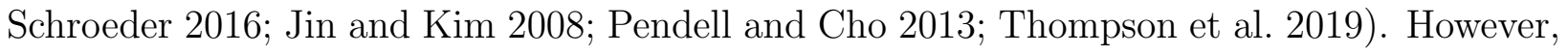
the initial negative shocks, on average, are of lower magnitude, possibly because ASF does not affect human health, and thus did not trigger meaningful adverse demand-side impacts on firm profitability. Figure 3 further shows that as time went on and ASF outbreaks continued, concerns over pork supply, which accounts for over $60 \%$ of China's meat consumption, deepened, resulting in anticipated surges of at least $5 \%$ in stock returns within 15 days after each outbreak. In particular, the sharp decline in hog and sow inventory at an increasing speed (a near-20\% loss) during January-February 2019 triggered investors' expectations that publicly-traded Chinese hog firms would earn large profits about six months later because

\footnotetext{
${ }^{12}$ Underreporting could occur in two ways - misreporting the scale or severity of the outbreaks, or not reporting an outbreak on a particular day. The first type of underreporting makes our current estimate a conservative estimate of the true stock price responses to ASF. This works in our favor, given that we have already quantified an abnormal stock return that is almost 10 times larger than previous research, despite this type of underreporting. We hypothesize that the second type of underreporting is more likely to have occurred during the early periods of ASF outbreaks when the scale and significance of the issue was less understood and had not risen to the level of a national food security issue nor caught the attention of top officials. To investigate the potential effects of the second type of underreporting issue on our event study results, we run a simulation that assumes ASF outbreaks occurred on 30 and 20 more randomly chosen days in August-December 2018 and January - September 2019, respectively, that MARA does not identify with ASF outbreaks. As such, we run the event study 1,000 times on both randomly generated and real ASF outbreaks. Based on the simulated experimental results, we conclude that the effects of the potential underreporting issue on the event study results are relatively small and our main conclusion is the same. The results will not be presented in detail here to save space, but they are available upon request.
} 
of the pig growth cycles (Sohu 2020; Volpelli 2017) ${ }^{13}$ This led to 9\% in CAAR within 10 days after an ASF announcement, which then surged to almost $20 \%$ over the 15-day span.

[Insert Figure 3. Cumulative average abnormal returns of Chinese hog firms for all ASF announcements.]

To better explain the mechanism behind these results, in Figure 4 we plot the percentage declines in both hog and sow inventories (year-on-year) against the monthly CAAR of Chinese hog firms. Note that, in Figure 4, we take the percentage declines in both hog and sow inventories as absolute value to better present the synchronous change relationship with the CAAR of Chinese hog firms. Figure 4 clearly shows that the percentage declines in both hog and sow inventories was relatively smooth in 2018, but have sharply deteriorated since January 2019. Specifically, the percentage decline in hog inventory in January 2019 $(-12.6 \%)$ was three times higher than that in December 2018 (-4.8\%). A more important indicator of future hog inventory and production, the percentage change in sow inventory, suddenly declined from $-8.3 \%$ in December 2018, to $-14.8 \%$ in January 2019 , to $-19.1 \%$ in February 2019 ${ }^{14}$ Together with huge pork demand during the Chinese Spring Festival, the above statistics issued by MARA at the beginning of 2019 sent clear signals to Chinese stock market investors that there would be a huge meat shortage and higher future hog prices in the following months, and that eventually publicly-traded hog firms would obtain huge profits from the future skyrocketing hog prices, which they did earn in late 2019 according to Chinese hog firms' 2019 annual reports. ${ }^{15}$

\footnotetext{
${ }^{13}$ According to the monthly hog inventory reports issued by MARA shown in Table A.2, in 2018, the percentage changes in hog inventory were relatively modest (the largest value in this period is less than $5 \%$ ). However, in January 2019, the percentage change in hog inventory significantly deteriorated from $-4.8 \%$ to $-12.6 \%$ - a total $20 \%$ loss at increasing speed. We also observe a similar pattern in sow inventory.

${ }^{14}$ Previous research shows the environmental regulations implemented from 2014 to 2017 at most led to a $8 \%$ decline in inventory in the eight southeast provinces (Cheng et al. 2020), and less than $5 \%$ nationally (Shao et al., 2021). The muted stock market responses until the prospect of at least a $20 \% \operatorname{loss}$ in hog or sow inventory suggests the environmental regulations are unlikely to explain our findings of strong CARs for hog firms.

${ }^{15}$ Note that a MARA press conference held on April 17, 2019, raised alarms about the future shortage of pork and predicted pork prices would rise 70\% in Q3 2019, which partly explains the CAR in April 2019 being statistically different from zero under the $5 \%$ significance level (see Figure 4 ).
} 
[Insert Figure 4: Percentage decline in in both hog and sow inventories (year on year) and monthly CAAR of Chinese hog firms.]

Firm-level stock price data allow us to further examine the heterogeneous effects on stock returns across hog firms. Using boxplots, Figure 5 shows individual distributions of the estimated CAR values for each of the 10 Chinese hog firms following every ASF outbreak during the four sub-sample periods and the overall statistical significance of the mean across firm-level CAR values ${ }^{16}$ Consistent with the overall effect on CAAR, we observe only modest negative effects on CAR for most firms in August 2018. Our findings are consistent with other food recall studies in terms of the direction and magnitude of the effects. Likewise, we observe that CAR values for firms were all significantly positive following ASF events, except for a limited number of firms, and that the effects were of higher magnitude from January to February 2019, similar to the findings shown in Figure 3. Figure 5; shows that Chinese hog firms, such as Tech-Bank Food, New Wellful, Tecon Animal Husbandry, and Tangrenshen Group, saw average ASF-induced stock returns reach as high as $20 \%-40 \%$, echoing our earlier demonstration that strong, positive stock returns reflect expectations of future pork supply shortages. We also note that previous food recall and animal disease outbreak studies typically report stock returns at less than 5\% (Thomsen and McKenzie 2001; Pozo and Schroeder 2016). Our findings of substantial positive returns reveal the importance of pork for Chinese consumers' daily diet and the severity of ASF outbreaks.

[Insert Figure 5. Cumulative abnormal returns of Chinese firms (a) in 08/2018, (b) from 09/2018 to $12 / 2018$, (c) from $01 / 2019$ to $02 / 2019$, (d) from $03 / 2019$ to $09 / 2019$.]

Event Study Results for Foreign Hog Firms. In contrast to Chinese hog firms, Figure 6 shows that all major global hog firms benefited from the severe reduction in China's domestic hog supply and the resulting surge in pork and meat import demand, which we

\footnotetext{
${ }^{16}$ Appendix Table A.3 provides test results that correspond to Chinese and foreign individual firm results shown in Figures 5 and 7 , and also tests results for Chinese firms' and foreign firms' CAAR that correspond to Figures 3 and 6
} 
observe consistently in all four sub-sample periods. We also find that foreign hog firms benefited the most during the Chinese Spring Festival. However, the estimated average CAAR values for global hog firms are much more modest than those of domestic Chinese hog firms, ranging from less than $1 \%$ to $3 \% 15$ event days after ASF announcements. This is likely because, although China's pork imports increased significantly following outbreaks, China's total annual pork imports (3 million tons in 2019), only represent about $6 \%$ of total domestic pork consumption. In other words, the delayed surge in pork imports helps explain the positive, yet modest, stock returns.

[Insert Figure 6; Cumulative average abnormal returns of foreign hog firms for all ASF announcements.]

Figure 7 helps explain the disparity in the level of disease outbreak effects by investigating firm-level CAR values for foreign firms. Similar to Figure 5, Figure 7 presents the estimated CAR values for individual firms over the first 15 days following each ASF announcement during the four sub-sample periods. We find that global hog firms initially exhibited mixed, and often insignificant, stock price responses to China's ASF outbreaks, which in part reflects uncertainty about the severity of impacts on China's hog production and import demand. As the massive drop in hog and sow inventories in China became evident during and after the 2019 Spring Festival, most global hog firms enjoyed modest, yet positive, stock returns every time China reported more ASF outbreaks. We note that there are large variations in firm-level stock returns in every period, and when averaging these firm-level returns we observe a smaller overall effect, as seen in Figure 6. However, we also observe that some global hog firms with larger Chinese market shares, especially Brazilian, Russian, Finnish, Thai, and Canadian firms, did experience greater positive stock returns after the Chinese New Year, which, together with our findings from Chinese firms, demonstrates that severe pork shortages induced more Chinese pork imports.

[Insert Figure 7: Cumulative abnormal returns of foreign firms (a) in 08/2018, (b) from 09/2018 to $12 / 2018$, (c) from $01 / 2019$ to $02 / 2019$, (d) from $03 / 2019$ to $09 / 2019$.] 
To examine if the U.S.-China trade war, which covers our entire estimation period, might confound our results for foreign hog firms - especially U.S., Brazilian, and Canadian firmswe present firm-level stock returns following ASF outbreaks for one Canadian, three U.S., and two Brazilian hog firms in Appendix Figure A.1. Appendix Figure A.1 shows that U.S. hog firms suffered, and Brazilian hog firms saw surging stock returns, when China announced retaliatory tariffs on U.S. exports. Similarly, Canadian stock returns fell following the tension between China and Canada over the arrest of a top Huawei executive, with corresponding bumps in Brazilian and U.S. stock returns. However, even though changes in trade situations affect immediate stock responses, they do not alter our fundamental findings of positive, yet moderate, stock returns for global hog firms following China's ASF outbreaks. The U.S.China trade war resulted in more variations and uncertainty in stock return responses by U.S. firms, while Brazilian firms, in general, enjoyed stable, positive stock returns when China's ASF outbreaks worsened.

Regression Results Explaining CARs. Finally, we present our regression results explaining the sources of abnormal returns. Table 1 shows that the one-lag CAR has a positive effect on current cumulative returns, which is consistent with the literature that past returns tend to carry a momentum to future returns (Fama and French 1988; Savor 2012). We find that Chinese hog firms with larger trading volumes in the stock market tend to enjoy greater stock returns following each ASF outbreak. While of a smaller magnitude, we find a negative lagged effect of trading volumes on CARs. We also observe that the public awareness of the ASF outbreaks is associated with a positive effect on the stock returns for the selected large firms, but the lagged effects tend to be mixed over time. Annual feeder pig prices serve as a proxy for production costs, and it is either negative and insignificant, or a positive contemporaneous effect on CAR that is balanced out by a stronger negative effect of the lagged feeder pig prices. The overall negative yet sometimes statistically insignificant relationship seems to suggest a higher production cost indicated by higher feeder pig prices could hurt hog firms' profits and CARs, but not much. However, we observe seemingly conflicting effects 
on CARs between whether the outbreak occurred on a large farm and whether the firm's pig farm was in the same county as the outbreak. Lastly, we also do not find conclusive evidence on the effects of the number of infected pigs and the share of a firm's hog producing and breeding income on CARs, both of which suggest that they are not salient predictors for CAR variations across ASF events.

[Insert Table 1; Regressions of Cumulative Abnormal Returns for Chinese Hog firms.]

Much like the results from Chinese hog firms, Table 2 shows that larger stock trading volumes are associated with positive stock returns after ASF events for foreign hog firms. Similarly, the severity of the event, measured in number of infected pigs, does not explain the movement of foreign firms' stock returns. The same observations seem to apply to the trading costs of selected foreign hog firms when we pool together the full sample. However, when we look at sub-periods separately, we observe that, in the early stages of the first ASF outbreak, exporters operating with higher trading costs are associated with decreased CARs. When the ASF situation gradually deteriorated by the beginning of 2019, companies with higher trading costs started enjoying positive CARs, as traders may have expected an increased demand for pork imports to China from these companies. Meanwhile, the public awareness of ASF outbreaks outside of China has a statistically significant and negative effect on CARs for global firms, and, unsurprisingly, the effect is relatively marginal compared to that of the public awareness in China. The fact that these effects are all of moderate magnitude suggests ASF outbreaks in China did not contribute much to the stock market performance of foreign hog firms, as these foreign firms also export to countries other than China. These findings are also supported from the event study results for foreign hog firms, where we only observe modest positive abnormal stock returns following ASF outbreaks.

[Insert Table 2: Regressions of Cumulative Abnormal Returns for Foreign Hog Firms.]

We conduct additional analyses to add credibility to our estimated results from Tables 1 and 2. First, we conduct the Kao (1999) panel cointegration test to examine whether 
our models in Equation (12) feature cointegrated relationships for both Chinese and foreign companies across different time periods (i.e., Table 1 columns 1-5 for Chinese companies and Table 2 columns 1-5 for foreign companies). Test results reject the null hypothesis of no cointegration across time periods for both Chinese and foreign regressions. We additionally run the Hadri Lagrange multiplier (LM) test (Hadri 2000) on the predicted panel of residuals from the ARDL estimation of Equation (12) and fail to reject the null hypothesis that all panels of predicted residuals from Equation (12) are stationary. These results together ensure that we performed the estimation of Equation (12) properly and that the results in Tables 1 and 2 should be reliable.

\section{Policy Implications}

ASF outbreaks have had profound and likely long-lasting impacts on Chinese and global hog industries. Our results of positive stock returns for global hog firms are consistent with China's surging meat import demand, which remains strong today. For example, the 2019-2020 U.S. pork exports to China reached a 10-year high, and the momentum is further building with the U.S.-China phase one trade deal (He et al. 2020). Despite the drastic cuts in China's current pork production capacity, ASF outbreaks might also come as a blessing in disguise, as they provide long-awaited opportunities for consolidation and modernization in China's hog industry.

First, ASF outbreaks present three important opportunities that are critical for the biosecurity and efficiency of China's future meat production. ASF disproportionately affected small-scale producers (MARA 2020), which are often inefficient (Tian 2017). Small-scale producers are losing out in the aftermath of ASF due to a lack of government support for compensation for culled or diseased pigs or paying for veterinary costs or other biosecurity measures in existing facilities to limit the spread of ASF (Guardian 2020). In addition, the new biosecurity requirements acted as a barrier to entry for small-scale farmers, and thus 
permitted big companies to achieve gains. Many provinces have recently banned restocking small-scale farms with fewer than 300 pigs (Sina 2019). As a result, the hog industry is more concentrated and reliant on large-scale farms. The number of pig farms that produce less than 49 heads per year, between 50 and 99 heads per year, and between 100 and 499 heads per year decreased by $16.4 \%, 18.7 \%$, and $12.5 \%$, respectively, in 2018 compared to 2017. On the contrary, the number of pig farms producing more than 50,000 heads per year increased $8.85 \%$ in that same time (MARA 2019, 2018), ${ }^{17}$ Furthermore, on December 16, 2020, MARA estimated that the commercial scale ratio of pig breeding will reach about $57 \%$ in $2020,4 \%$ higher than in 2019, and much higher than the average growth of $2 \%$ in the past years (XinhuaNet 2020). This is consistent with Russia's ongoing ASF experience that started in November 2007. As a result, the proportion of Russian pork production in commercial hog farms increased from $42 \%$ in 2007 to $86 \%$ in 2018, but the total pork production increased from 1.64 million tons in 2007 to 3.16 million tons in 2018 (Ping An Securities Co. Ltd. 2019). The large hog firms we analyze in this study have sped up investment and acquisition of large-scale hog farms. For example, Wens Foodstuff Group, the largest hog firm in China, announced in November 2019 that it had acquired a large farm in central China with an annual production capacity of 28,000 sows and 700,000 pigs (Zhu 2019).

Second, we conjecture that ASF will accelerate current improvements in China's pork production efficiency by further using genome selection technology and upgrading the infrastructure of pig farms. For example, Muyuan Foodstuff invested heavily in genetic improvement and now has more than 800 professional breeding researchers, an internationally advanced PIGBLUP software, a genetic evaluation system for pigs, and professional meat quality testing equipment (Muyuan Foodstuff|2020). Muyuan's production efficiency increase is consistent with the United States' experience. Over the past three decades, the United States has reduced sow inventories, but still produces $60 \%$ more pork than it did in 1990 due to technical innovations in both breeding and genetic research as well as improvements in

\footnotetext{
${ }^{17}$ The China Animal Husbandry Veterinary Yearbooks published in 2018 and 2019 contain data and statistics for 2017 and 2018, respectively.
} 
nutrition and barn management practices (USDA-ERS 2016) 18 Arguably, the larger-scale commercial hog farms are more efficient in production than the backyard farms that represented $40 \%$ of China's hog inventories before the ASF outbreaks (Essig 2020). Furthermore, a higher level of market concentration in the upstream and midstream segments (i.e., having more large-sized producers and processors to replace the large number of small producers), may be conducive to efficiency improvement and quality control (Zhang et al. 2019).

Third, capital gains through the positive stock returns incentivized investments and upgrades of the large hog firms analyzed in our paper. The severe pork shortage led to skyrocketing pork prices in 2019, and the hog firms earned record profits in the third and fourth quarters of 2019 due to the skyrocketing pork prices. For example, Muyuan Foods, China's number two producer, said that full-year profits for 2019 surged more than $1,000 \%$ to 6.1 billion yuan (\$869.84 million) thanks to record hog prices caused by a plunge in supplies. The record profits will give hog firms cash reserves to invest in biosecurity and larger hog farms with advanced production technologies such as breeding automation (Sina 2020c), independent ventilation and artificial-intelligence-enabled pig disease prediction model (Sina) 2020b). These innovations could lead to a more efficient and globally competitive hog sector in China.

Fourth, ASF outbreaks have spurred deeper supply chain integration and structural transformation of China's food sector. The top Chinese pig-breeding firms have begun entering the slaughtering and processing industry (GlobalMeatNews 2019; Sina 2020a), in part due to recognition of the fact that $70 \%$ of ASF outbreaks are related to China's heavily used live animal transportation system (Watch 2019). The popularity of live pig transportation is a result of Chinese consumers' long-held preferences for fresh pork over chilled or frozen pork. ASF outbreaks have served as a wake-up call for pig breeding firms to enter the slaughter-

\footnotetext{
${ }^{18}$ In 1980, the United States produced 7.53 million tons of pork based on 9.63 million sows; however, in 2019 , the number of sows in inventory fell to 6.29 million, but pork production was 12.56 million tons. If the production efficiency is measured by the production of meat per head of sow, then efficiency increased about $156 \%$ - production per head continuously increased from 0.78 tons/head in 1980 to 2 tons/head in 2019 (Ping An Securities Co. Ltd. 2019). At the same time, marketed pigs per sow per year (MSY) also continued to increase from 10.6 in 1980 to 22.1 in 2019 (Ping An Securities Co. Ltd. 2019).
} 
ing industry and transition into chilled meat transportation as cold chain logistics of meat products have improved. Two major cities in Guangdong province stopped supplying fresh pork in December 2018 in favor of providing chilled and frozen pork only (Sohu 2018). Hog firms are also increasing investment in the feedstuff industry and pig breeding industry (Zhu 2019; Sina 2020a). In other words, the Chinese hog industries are, and will continue to be, more concentrated and more vertically integrated following the ASF outbreaks.

\section{Conclusions}

The ongoing ASF outbreaks in China, the Philippines, Germany and several other countries have been among the most consequential events in the global food sector. ASF has caused roughly a $20 \%$ reduction in the global pig inventory and its impacts are consequential for global food production and far from over. By quantifying the abnormal stock returns induced by ASF, we provide the first systematic evaluation of the unintended financial impacts of China's ASF outbreaks on Chinese and global hog firms. We find that, contrary to conventional wisdom, on average, ASF outbreak announcements led to positive and significant stock returns for both Chinese and international hog firms. This differs from the past literature on animal disease outbreaks and food recalls in two ways. First, we only detect a drop in stock returns for Chinese hog firms following China's first ASF outbreak. Second, we find that Chinese hog firms, on average, enjoyed 10\%-40\% CARs within 15 days of an ASF event announcement during the 2019 Chinese Spring Festival. The abnormal return is positive and has a magnitude up to 10 times larger than that of previous food recall studies (Pozo and Schroeder 2016).

Our findings of positive stock returns following ASF events have important policy im-

plications. In contrast to other food safety issues, worries about supply reductions and shortages resulted in significant and positive stock returns, as opposed to the negative stock price movements following weakened demand for recalled or banned food products. Although 
key events in the U.S.-China trade war could explain some stock return movements, our general finding of modest, yet positive, returns for global hog firms are robust. Our results of supply-shortage-induced stock returns are consistent with China's meat import surge, and also indicative of possible significant consolidation opportunities by the hog firms analyzed in our paper, leading to a more concentrated and vertically integrated Chinese hog sector. The degree to which the Chinese hog industry will consolidate, and the implication for market outcomes, are both critical issues and are left for further exploration in future work.

We note three important assumptions and limitations regarding the selection of data and the length of our sample period. First, although more than half of China's pork imports come from Europe, we do not consider several giant European hog firms - such as the Tonnies Group in Germany, Cooperl Arc Atlantique and Aveltis in France, Vall Companys and Piensos Costa in Spain, Goodvalley and Danish Crown AmbA in Denmark, and Vion Food Group in the Netherlands - because they are private firms and not publicly traded on stock markets. However, our analysis of foreign hog firms includes firms that account for one-third of global pork exports, and the private firms' stock returns are somewhat similar to the patterns we uncover. Second, more than $80 \%$ of China's pork is produced in small-scale or backyard production, so the 10 Chinese hog firms we analyze typically have better bio-security measures and do not reflect the performance and profitability of the overall hog industry. Yet, as discussed earlier, ASF outbreaks will result in more consolidation and modernization of China's hog industry and the corresponding food supply chain. Consequently, our analysis is even more salient in understanding the future of China's food industry. Finally, without detailed data on firm-level pork and immediate hog prices and production costs, we can only offer suggestive evidence regarding the mechanisms of the hog firms' profit formation. These important micro-level responses and the pass-through and distributional effects of profits across the Chinese hog supply chain are left for future research. 


\section{References}

Acharya, S. (1993). Value of latent information: Alternative event study methods. The Journal of Finance, 1:363-385.

Aitken, M. J. and Swan, A. F. M. M. P. (2010). Short sales are almost instantaneously bad news: Evidence from the australian stock exchange. Journal of Finance, 53(2):2205-2223.

Bai, Z., Jin, S., Wu, Y., zu Ermgassen, E., Oenema, O., Chadwick, D., Lassaletta, L., Velthof, G., Zhao, J., and Ma, L. (2019). China's pig relocation in balance. Nature Sustainability, 2(10):888-888.

Bai, Z., Ma, W., Ma, L., Velthof, G. L., Wei, Z., Havlík, P., Oenema, O., Lee, M. R. F., and Zhang, F. (2018). China's livestock transition: Driving forces, impacts, and consequences. Science Advances, 4(7):eaar8534.

Beltrán-Alcrudo, D., Arias, M., Gallardo, C., Kramer, S., and Penrith, M. (2017). African Swine Fever: detection and diagnosis - a manual for veterinarians. http://www.fao.org/3/a-i7228e.pdf.

Bera, A., Bubnys, E., and Park, H. (1988). Conditional heteroscedasticity in the market model and efficient estimates of betas. Financial Review, 23(2):201-214.

Black, B. and Kim, W. (2012). The effect of board structure on firm value: A multiple identification strategies approach using korean data. Journal of Financial Economics, 104(1):203-226.

Bloomberg (Sept. 2020). Deadly hog fever found in germany, europe's top pork producer. https://www.bloomberg.com/news/articles/2020-09-09/germany-has-suspectedcase-of-african-swine-fever-ministry-says.

Boehmer, E., Masumeci, J., and Poulsen, A. B. (1991). Event-study methodology under conditions of event-induced variance. Journal of Financial Economics, 30(2):253-272.

Bollerslev, T. (1986). Generalized autoregressive conditional heteroskedasticity. Journal of Econometrics, 31(3):307-327.

Bollerslev, T., Chou, R. Y., and Kroner, K. F. (1992). ARCH modeling in finance: A review of the theory and empirical evidence. Journal of Econometrics, 52(1):5-59.

Brown, S. J. and Warner, J. B. (1980). Measuring security price performance. Journal of Financial Economics, 8(3):205-258.

Carriquiry, M., Elobeid, A., Swenson, D., and Hayes, D. (2020). Impacts of African Swine Fever in Iowa and the United States. CARD Working Paper 20-WP 600, Center for Agricultural and Rural Development, Iowa State University.

Chand, A. (2020). Putting African Swine Fever on ice. Nature Food, 1(1):16-16. 
Chavas, J.-P. and Holt, M. T. (1991). On nonlinear dynamics: The case of the pork cycle. American Journal of Agricultural Economics, 73(3):819-828.

Cheng, N., Zhang, W., and Xiong, T. (2020). The impact of china's location based environmental regulations on hog industry and water quality: A synthetic difference-in-differences approach. Agricultural and Applied Economics Association 2020 Annual Meeting.

Coakley, J., Thomas, H., and Wang, H. M. (2008). The short-run wealth effects of foreign divestitures by uk firms. Applied Financial Economics, 18(3):173-184.

Corhay, A. and Rad, A. T. (1996). Conditional heteroskedasticity adjusted market model and an event study. Quarterly Review of Economics \& Finance, 36(4):529-538.

Corrado, C. J. (2011). Event studies: A methodology review: Accounting and finance. Accounting 8 Finance, 51(1):207-234.

Doidge, C. and Dyck, A. (2015). Taxes and corporate policies: Evidence from a quasi natural experiment. Journal of Finance, 70(1):45-89.

Engle, R. (2001). The use of arch/garch models in applied econometrics. Journal of Economic Perspectives, 15(4):p.157-168.

Essig, M. (2020). A quarter of the global pig population has been wiped out. Here is why. https://www.washingtonpost.com/opinions/2020/01/06/why-global-swine-feverepidemic-is-hitting-poor-people-hardest/.

Fama, E. F., Fisher, L., Jensen, M. C., and Roll, R. (1969). The adjustment of stock prices to new information. International economic review, 10(1):1-21.

Fama, E. F. and French, K. R. (1988). Dividend yields and expected stock returns. Journal of Financial Economics, 22(1):3-25.

FAO (2021). Asf situation in asia \& pacific update (29 april 2021). http://www.fao.org/ag/againfo/programmes/en/empres/ASF/situation_update.html.

Giaccoto, G. and Ali, M. M. (1982). Optimal distribution free tests and further evidence of heteroskedasticity in the market model. Journal of Finance, 37:1247-1257.

GlobalMeatNews (March 2019). China breeder increases slaughtering capacity. $\quad$ https://www.globalmeatnews.com/Article/2019/03/12/Muyuan-Foods-increasesslaughter-capacity.

Guardian, T. (2020). African Swine Fever destroying small pig farms, as factory farming booms. https://www.theguardian.com/environment/2020/mar/11/african-swinefever-destroying-small-pig-farms-as-factory-farming-booms-report.

Hadri, K. (2000). Testing for stationarity in heterogeneous panel data. The Econometrics Journal, 3(2):148-161. 
He, X., Hayes, D. J., and Zhang, W. (2020). China's agricultural imports under the phase one deal: Is success possible? CARD Policy Briefs 20-PB 29, Center for Agricultural and Rural Development, Iowa State University.

Hjalmarsson, E. (2011). New methods for inference in long-horizon regressions. Journal of Financial and Quantitative Analysis, 46(3):815-839.

Jin, H. J. and Kim, J.-C. (2008). The effects of the BSE outbreak on the security values of US agribusiness and food processing firms. Applied Economics, 40(3):357-372.

Kao, C. (1999). Spurious regression and residual-based tests for cointegration in panel data. Journal of Econometrics, 90(1):1-44.

Kaspereit, T. (2015). eventstudy2: Stata module to perform event studies with complex test statistics,. Statistical Software Components, S458086.

Kolari, J. W. and Pynnönen, S. (2010). Event study testing with cross-sectional correlation of abnormal returns. The Review of financial studies, 23(11):3996-4025.

Kolbasov, D., Titov, I., Tsybanov, S., Gogin, A., and Malogolovkin, A. (2018). African swine fever virus, siberia, russia, 2017. Emerging Infectious Diseases, 24(4):796.

Lee, H., Kim, S., and Kim, J. (2012). Open technology innovation activity and firm value: evidence from korean firms. Applied Economics, 44(25-27):3551-3561.

Liu, J., Arndt, C., and Hertel, T. W. (2004). Parameter estimation and measures of fit in a global general equilibrium model. Journal of Economic Integration, 19(3):626-649.

Liu, S., Luo, Y., Wang, Y., Li, S., Zhao, Z., Bi, Y., Sun, J., Peng, R., Song, H., Zhu, D., Sun, Y., Li, S., Zhang, L., Wang, W., Sun, Y., Qi, J., Yan, J., Shi, Y., Zhang, X., Wang, P., Qiu, H.-J., and Gao, G. F. (2019). Cryo-EM structure of the African Swine Fever virus. Cell Host \& Microbe, 26(6):836-843.e3.

Ljung, G. M. and Box, G. E. P. (1978). On a measure of lack of fit in time series models. Biometrika, 65(2):297-303.

Lusk, J. L. and Schroeder, T. C. (2002). Effects of meat recalls on futures market prices. Agricultural and Resource Economics Review, 31(1):47-58.

MacKinlay, A. C. (1997). Event studies in economics and finance. Journal of Economic Literature, 35(1):13-39.

Mallapaty, S. (2019). Spread of deadly pig virus in China hastens vaccine research. Nature, $569(7754): 13-14$.

MARA (2018). China Animal Husbandry Veterinary Yearbook 2018. https://data.cnki.net/trade/Yearbook/Single/N2019070177?z=Z009.

MARA (2019). China Animal Husbandry Veterinary Yearbook 2019. https://data.cnki.net/trade/Yearbook/Single/N2019070177?z=Z009. 
MARA (2020). Announcements of African Swine Fever outbreaks in China (in Chinese). http://www.moa.gov.cn/gk/yjgl_1/yqfb/.

Maskara, P. K. and Mullineaux, D. J. (2011). Information asymmetry and self-selection bias in bank loan announcement studies. Journal of Financial Economics, 101(3):684-694.

Mason-D'Croz, D., Bogard, J. R., Herrero, M., Robinson, S., Sulser, T. B., Wiebe, K., Willenbockel, D., and Godfray, H. C. J. (2020). Modelling the global economic consequences of a major African Swine Fever outbreak in China. Nature Food, 1(4):221-228.

Moon, D. and Tonsor, G. T. (2020). How do e. coli. recalls impact cattle and beef prices? Journal of Agricultural and Resource Economics, 45(1):92-106.

Morgan, A. and Morgan, L. (1987). Measurement of abnormal returns from small firms. Journal of Business and Economics Statistics, 5(5):121-129.

Muyuan Foodstuff (2020). Muyuan foodstuff established a breeding system to improve pork quality and create more value for all members of the pork production chain (in Chinese). http://www.muyuanfoods.com/index.php/52f596d90a.

Novy, D. (2013). Gravity redux: measuring international trade costs with panel data. Economic Inquiry, 51(1):101-121.

O'hara, M. and Shaw, W. (1990). Deposit insurance and wealth effects: the value of being "too big to fail". The Journal of Finance, 45(5):1587-1600.

Pendell, D. L. and Cho, C. (2013). Stock market reactions to contagious animal disease outbreaks: An event study in Korean foot-and-mouth disease outbreaks. Agribusiness, 29(4):455-468.

Pig66 (2019). Yangxiang's intelligent multi-floor boar stud (in Chinese). https://www.pig66.com/2019/139_1023/18309874.html.

Ping An Securities Co. Ltd. (2019). 2020 annual strategy report of agriculture, forestry, animal husbandry and fishery industry (in Chinese). https://pdf.dfcfw.com/pdf/H3_AP201912161371862679_1.pdf?1576511299000.pdf.

Pozo, V. F. and Schroeder, T. C. (2016). Evaluating the costs of meat and poultry recalls to food firms using stock returns. Food Policy, 59:66-77.

Saefong, M. P. (Aug. 2018). Hog prices poised to soar as deadly swine disease emerges in China. https://www.marketwatch.com/story/hog-prices-poised-to-soar-as-deadly-swinedisease-emerges-in-china-2018-08-31.

Salin, V. and Hooker, N. H. (2001). Stock market reaction to food recalls. Review of Agricultural Economics, 23(1):33-46.

Savor, P. G. (2012). Stock returns after major price shocks: The impact of information. Journal of Financial Economics, 106(3):635-659. 
Shao, Y., Li, M., Zhang, W., Ji, Y., and Hayes, D. (2018). World's largest pork producer in crisis: China's African Swine Fever outbreak. Agricultural Policy Review, Fall 2018:1-4.

Shao, Y., Xiong, T., Li, M., Hayes, D., Zhang, W., and Xie, W. (2021). China's missing pigs: Correcting china's hog inventory data using a machine learning approach. American Journal of Agricultural Economics, 103(3):1082-1098.

Sina (Feb. 2019). The hog industry in the shadow of African Swine Fever (in Chinese). http://finance.sina.com.cn/roll/2019-02-14/doc-ihqfskcp4992409.shtml.

Sina (Jan. 2020c). Wens Foodstuff Group's fourth-generation pig farm landed in Guangdong (in Chinese). https://tech.sina.com.cn/roll/2020-01-07/doc-iihnzahk2610314.shtml.

Sina (March 2020a). Huatong Meat plans to build a breeding farm with a total investment of US\$ 4.18 million to expand the scale of its pig breeding (in Chinese). http://finance.sina.com.cn/stock/relnews/cn/2020-03-13/doc-iimxxstf8821864.shtml.

Sina (March 2020b). Muyuan's "online" Q \& A expected the number of breeding sows to double by the end of the year (in Chinese). http://finance.sina.com.cn/roll/2020-0307/doc-iimxyqvz8532570.shtml.

Sohu (Aug. 2020). Ministry of Agriculture and Rural Areas: 5-6 months after the pig market will fundamentally reverse the situation of tight market supply (in Chinese). https://www.sohu.com/a/413963254_120050990.

Sohu (Dec. 2018). Shenzhen and Dongguan stopped supplying fresh pork (in Chinese). https://www.sohu.com/a/284124319_799561.

Spickler, A. R. (2019). African Swine Fever. http://www.cfsph.iastate.edu/DiseaseInfo/factsheets.php.

Thompson, J. M., Trejo-Pech, C. J., and Pendell, D. L. (2019). Agribusiness value impacts from highly pathogenic avian influenza. Agricultural Finance Review, 79(3):371-385.

Thomsen, M. R. and McKenzie, A. M. (2001). Market incentives for safe foods: An examination of Shareholder Losses from meat and poultry recalls. American Journal of Agricultural Economics, 83(3):526-538.

Tian, X. and von Cramon-Taubadel, S. (2020). Economic consequences of African Swine Fever. Nature Food, 1(4):196-197.

Tian, Y. (2017). Live pig production efficiency in China. University of California, Davis.

USDA-ERS (Jan. 2016). More pork produced with fewer breeding animals, as sow productivity increases. https://www.ers.usda.gov/data-products/chart-gallery/gallery/chartdetail/?chartId $=78724$.

USDA-FAS (2020). Export Forecasts Lowered for Beef \& Chicken in 2020. https://apps.fas.usda.gov/psdonline/circulars/livestock_poultry.pdf. 
van Tongeren, F., van Meijl, H., and Surry, Y. (2001). Global models applied to agricultural and trade policies: A review and assessment. Agricultural Economics, 26(2):149-172.

Volpelli, L. A. (Aug. 2017). Manual of good practices in pig farming. https://www.rtm.ong/download/Manual_Eng_Final.pdf.

Wang, N., Zhao, D., Wang, J., Zhang, Y., Wang, M., Gao, Y., Li, F., Wang, J., Bu, Z., Rao, Z., and Wang, X. (2019). Architecture of African Swine Fever virus and implications for viral assembly. Science, 366(6465):640-644.

Watch, A. (2019). Transport pigs into meat: The big changes in the pig industry to come. https://news.zhuwang.cc/xingyedianping/20190419/391010.html.

XinhuaNet (Dec. 2020). Pig production speed up, recovery and development quality improved significantly (in Chinese). http://www.xinhuanet.com/food/202012/16/c_1126866463.htm.

Yangxiang Co. Ltd. (2020). Intelligent pig raising. https://yangxiang.com/english-textindex2-22200.html.

Zhang, H., Wang, J., and Martin, W. (2018). Factors affecting households' meat purchase and future meat consumption changes in China: A demand system approach. Journal of Ethnic Foods, 5(1):24-32.

Zhang, Y., Rao, X., and Wang, H. H. (2019). Organization, technology and management innovations through acquisition in china's pork value chains: The case of the smithfield acquisition by shuanghui. Food Policy, 83:337-345.

Zhou, X., Li, N., Luo, Y., Liu, Y., Miao, F., Chen, T., Zhang, S., Cao, P., Li, X., Tian, K., et al. (2018). Emergence of African Swine Fever in China, 2018. Transboundary and Emerging Diseases, 65(6):1482-1484.

Zhu, W. (Dec. 2019). Pig farming gets a welcome boost. https://www.chinadaily.com.cn/a/201912/06/WS5de9bf15a310cf3e3557c637.html. 


\section{Figures and Tables}

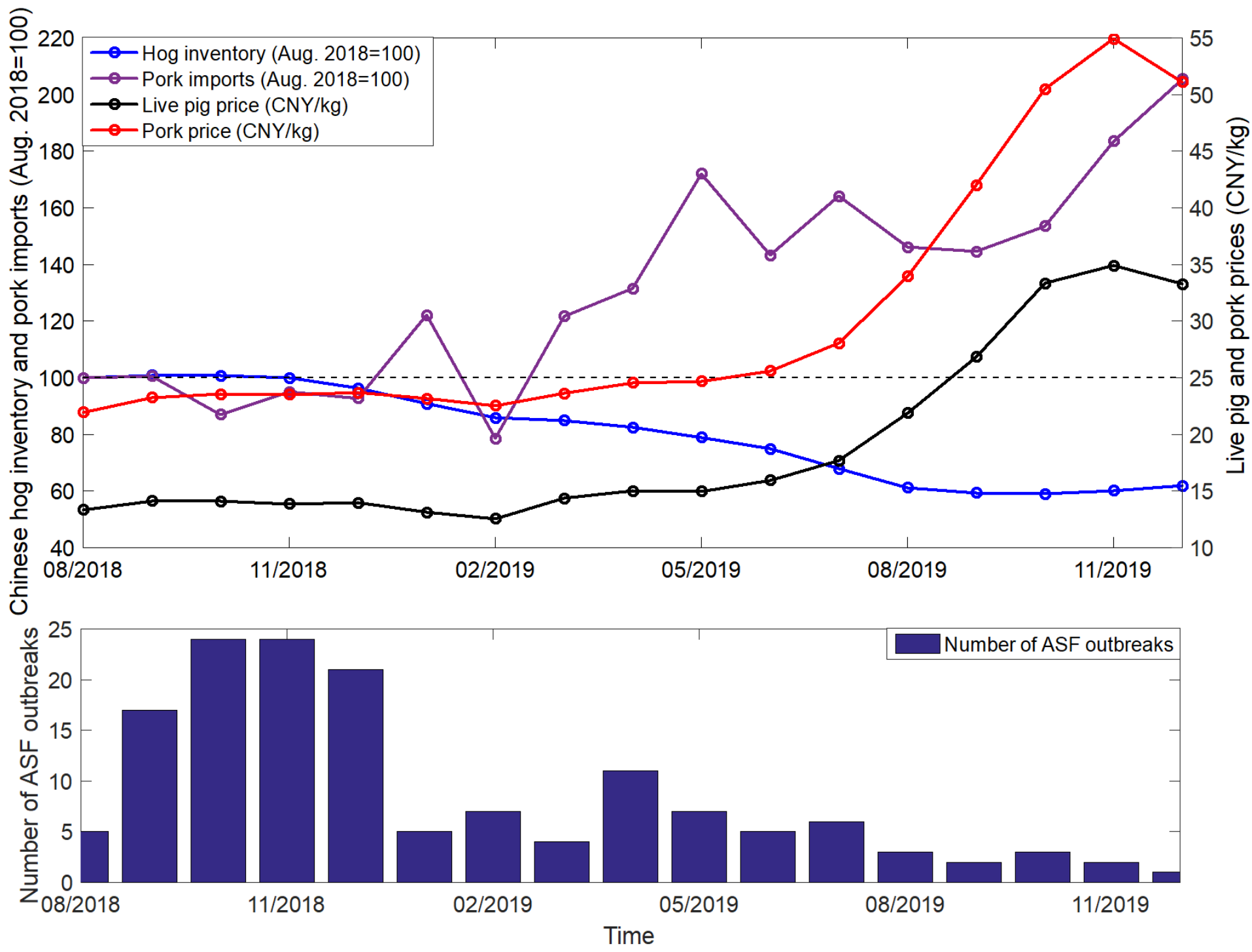

Figure 1: Chinese hog inventory, pork imports, and prices of live hog and pork (top) and ASF outbreak timeline (bottom)

Notes: In the top figure, the left axis shows monthly hog inventory and pork imports in percentage changes, using August 2018 as the baseline value of 100 and the right axis shows monthly actual live hog and pork prices $(\mathrm{CNY} / \mathrm{kg})$. The number of ASF outbreaks is also aggregated to monthly level in the bottom figure. 

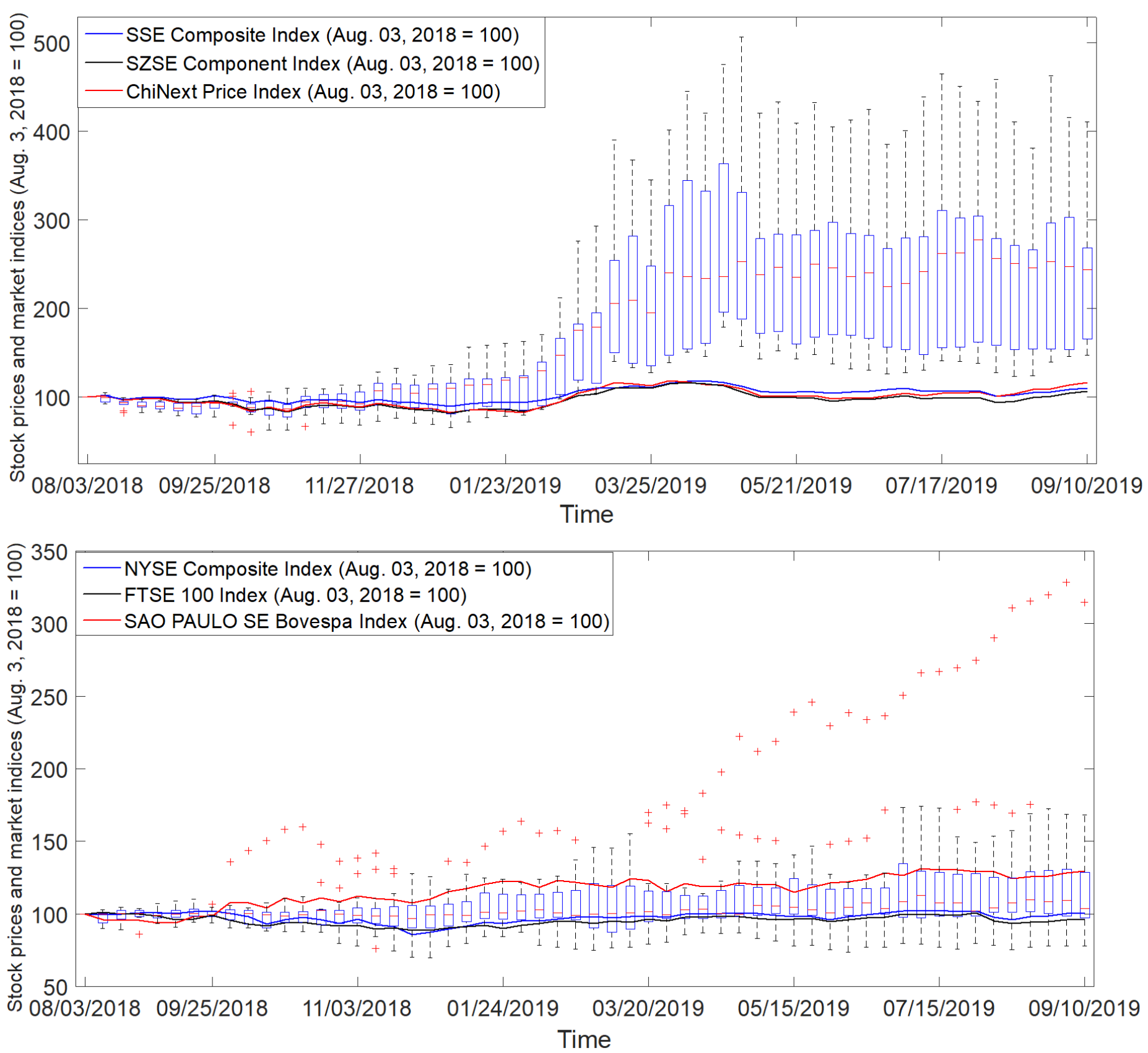

Figure 2: Stock price changes of Chinese and global hog firms following China's ASF outbreak.

Notes: The top figure shows the evolutions of the Shanghai Stock Exchange (SSE) Composite Index, Shenzhen Stock Exchange (SZSE) Component Index, and ChiNext Price Index. The bottom figure shows the evolutions of the New York Stock Exchange (NYSE) Composite Index, Financial Times Stock Exchange (FTSE) 100 Index, and Sao Paulo Stock Exchange Bovespa Index. We use 08/03/2018 as the base period with the assigned value of 100 in both figures. In addition to the market indices, we present the distribution of weekly stock prices for 10 Chinese hog firms and 15 global hog firms with boxplots in the top and bottom figures, respectively. The bottom edge, the horizontal red line in the middle, and the top edge of each blue box represents the 25 th percentile, median, and 75 th percentile of the distribution, respectively. Whiskers shown in black extending beyond the box denote the minimum and maximum stock price values. Each + symbol in red indicates an outlier. 


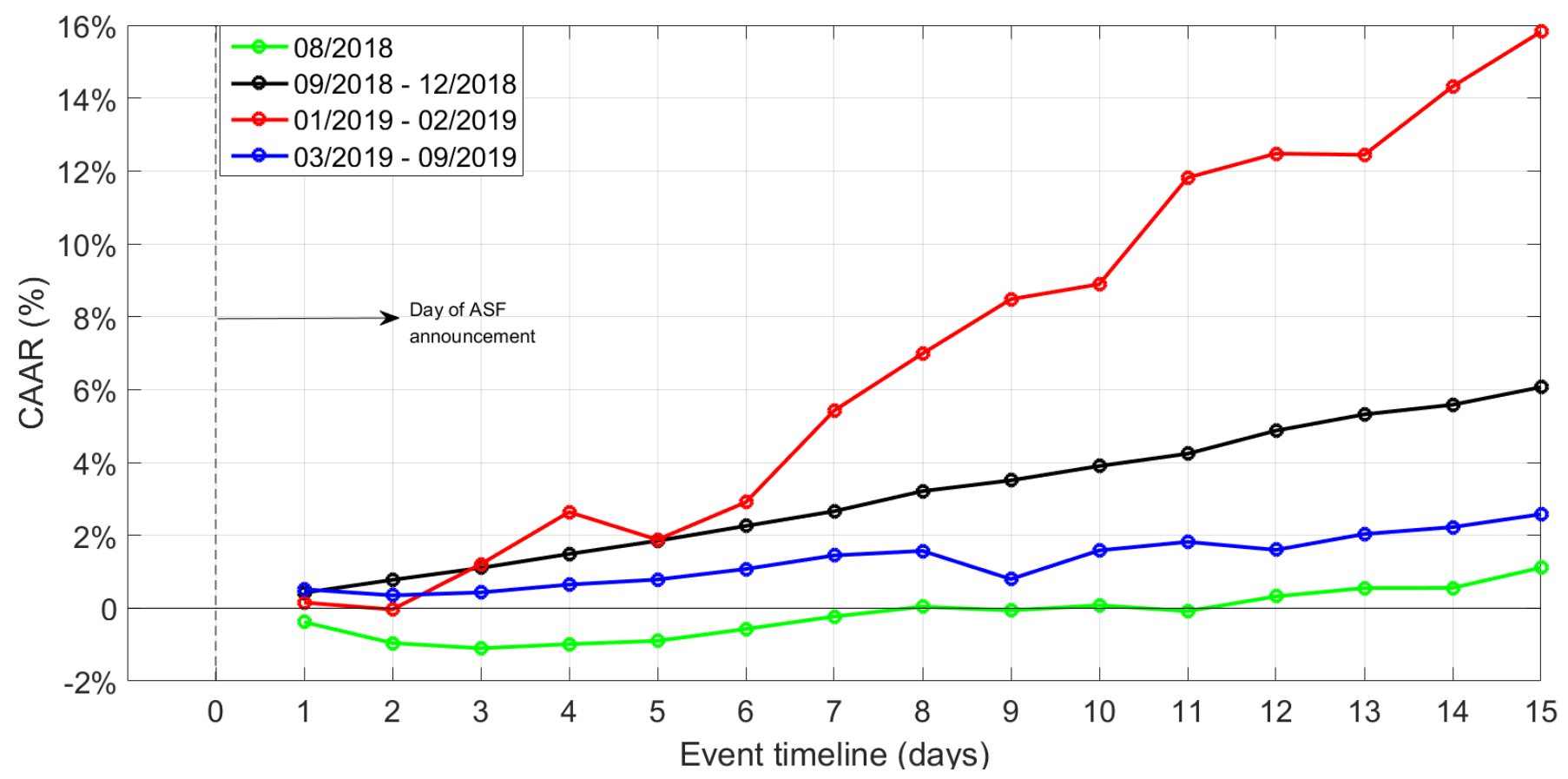

Figure 3: Cumulative average abnormal returns (CAAR) of Chinese hog firms for all ASF announcements.

Notes: The vertical axis refers to CAAR values and the horizontal axis displays the event days since an ASF outbreak (at time 0). For each subsample period, every data point is a CAAR over a 1-day span, a 2-day span, and so on to a 15-day span since an ASF outbreak, respectively. The statistical significance of each CAAR is presented in Appendix Table A.3. 


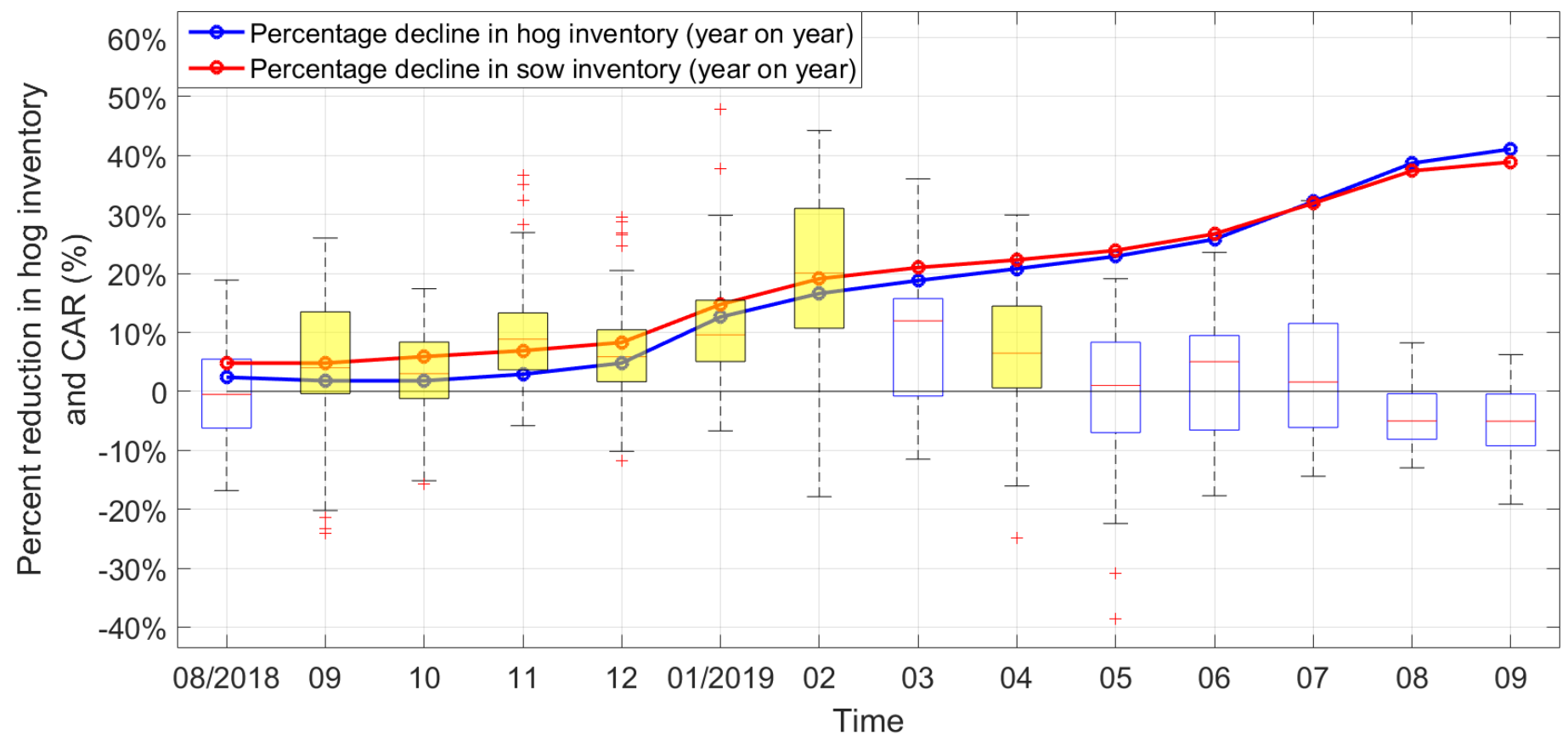

Figure 4: Percentage declines in both hog and sow inventories and monthly CAAR of Chinese hog firms.

Notes: We take the percentage declines in both hog and sow inventories as absolute value to better present the synchronous change relationship with the CAAR of Chinese hog firms. In this figure we present the distribution of Chinese hog firms' CAR values from all ASF events in each month. CAR values are calculated by accumulating the abnormal returns from our event-study model for 15 trading days since each event $\left(\tau_{1}=1, \tau_{2}=15\right)$. The vertical axis is CAR values in percentage change $(\%)$. Each box, moving from the bottom edge to the middle line and to the top edge is the 25 th percentile, median, and 75 th percentile of the distribution. Whiskers extending from the box connect the minimum and maximum CAR values. A box highlighted in yellow indicates that the average value is statistically different from zero from the adjusted BMP $t$-test under the significance level of $5 \%$, and is blank otherwise. Each + symbol in red indicates an outlier that is not included in the test sample. 
(a) $08 / 2018$

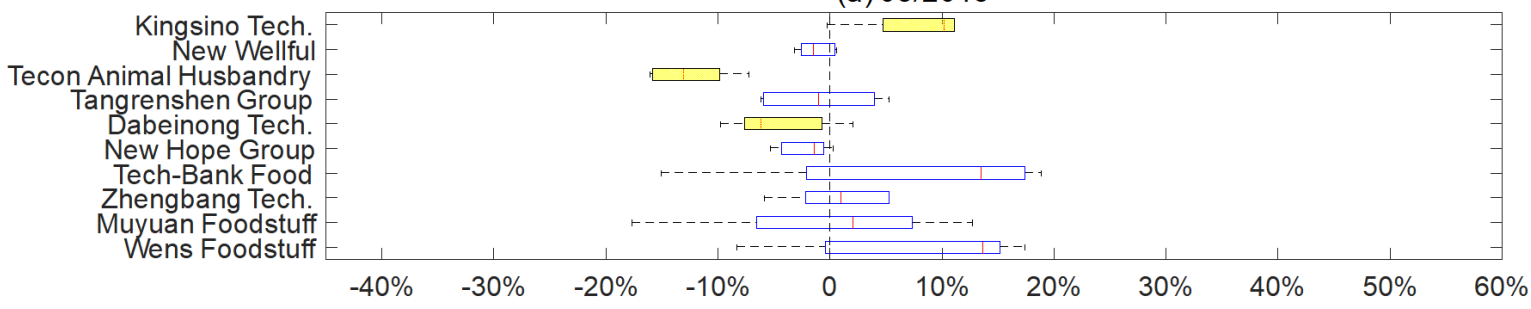

(b) $09 / 2018-12 / 2018$

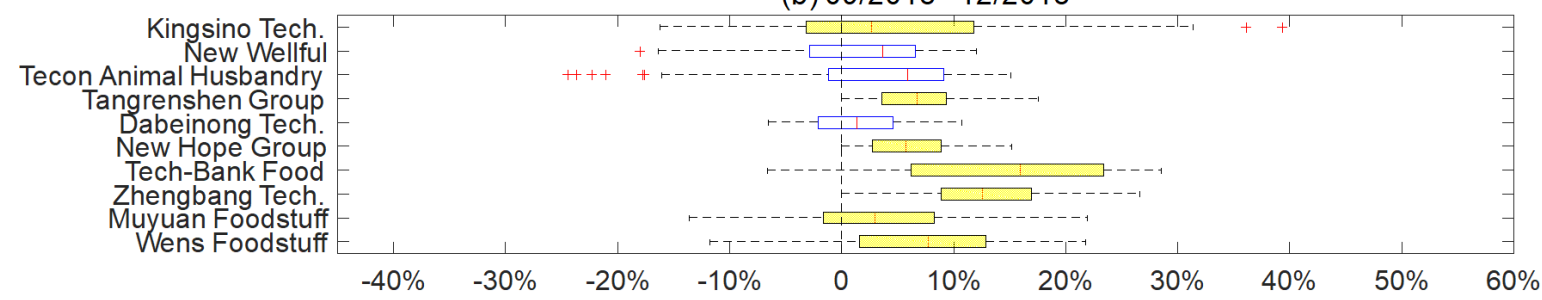

(c) $01 / 2019-02 / 2019$

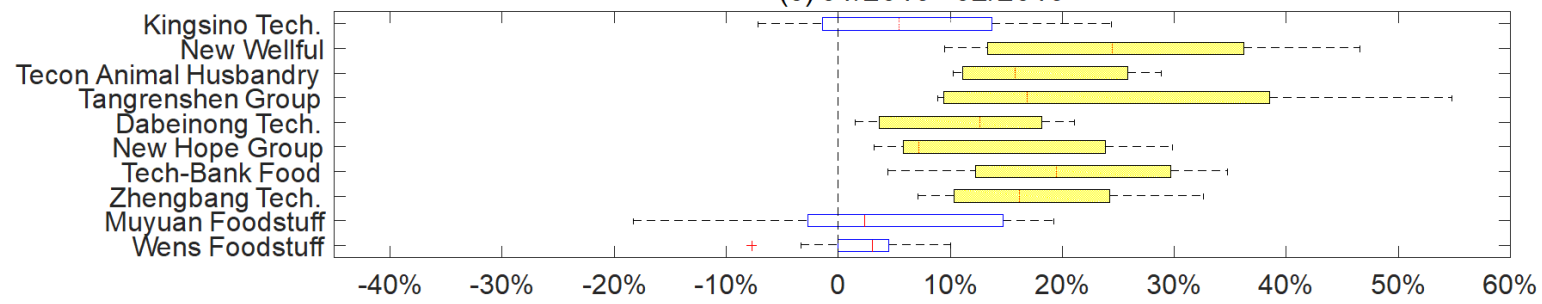

(d) $03 / 2019-09 / 2019$

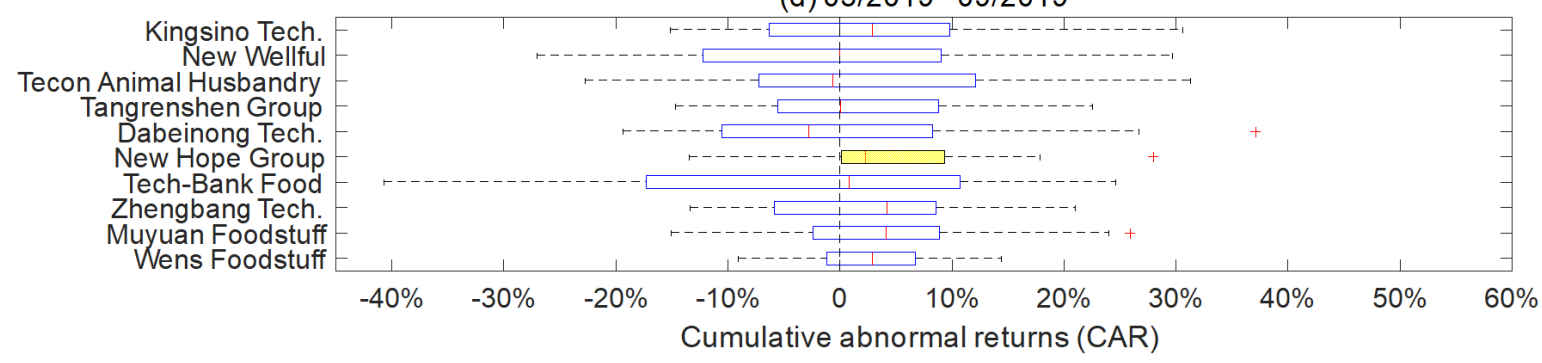

Figure 5: Cumulative abnormal returns (CAR) of Chinese firms (a) in 08/2018, (b) from 09/2018 to $12 / 2018$, (c) from $01 / 2019$ to $02 / 2019$, (d) from $03 / 2019$ to $09 / 2019$.

Notes: In each figure, we present the distribution of firm-specific CAR values from all ASF events within each subsample period. CAR values are calculated by accumulating the abnormal returns from our event-study model for 15 trading days since each event $\left(\tau_{1}=1, \tau_{2}=15\right)$. The vertical axis displays the top 10 Chinese hog firms (in no particular order) and the horizontal axis is CAR values in percentage change (\%). Each box, moving from the left edge to the middle line and to the right edge is the 25 th percentile, median, and 75th percentile of the distribution. Whiskers extending from the box connect the minimum and maximum CAR values. A box highlighted in yellow indicates that the average value is statistically different from zero from the adjusted BMP $t$-test under the significance level of $5 \%$, and is blank otherwise. Each + symbol in red indicates an outlier that is not included in the test sample. 


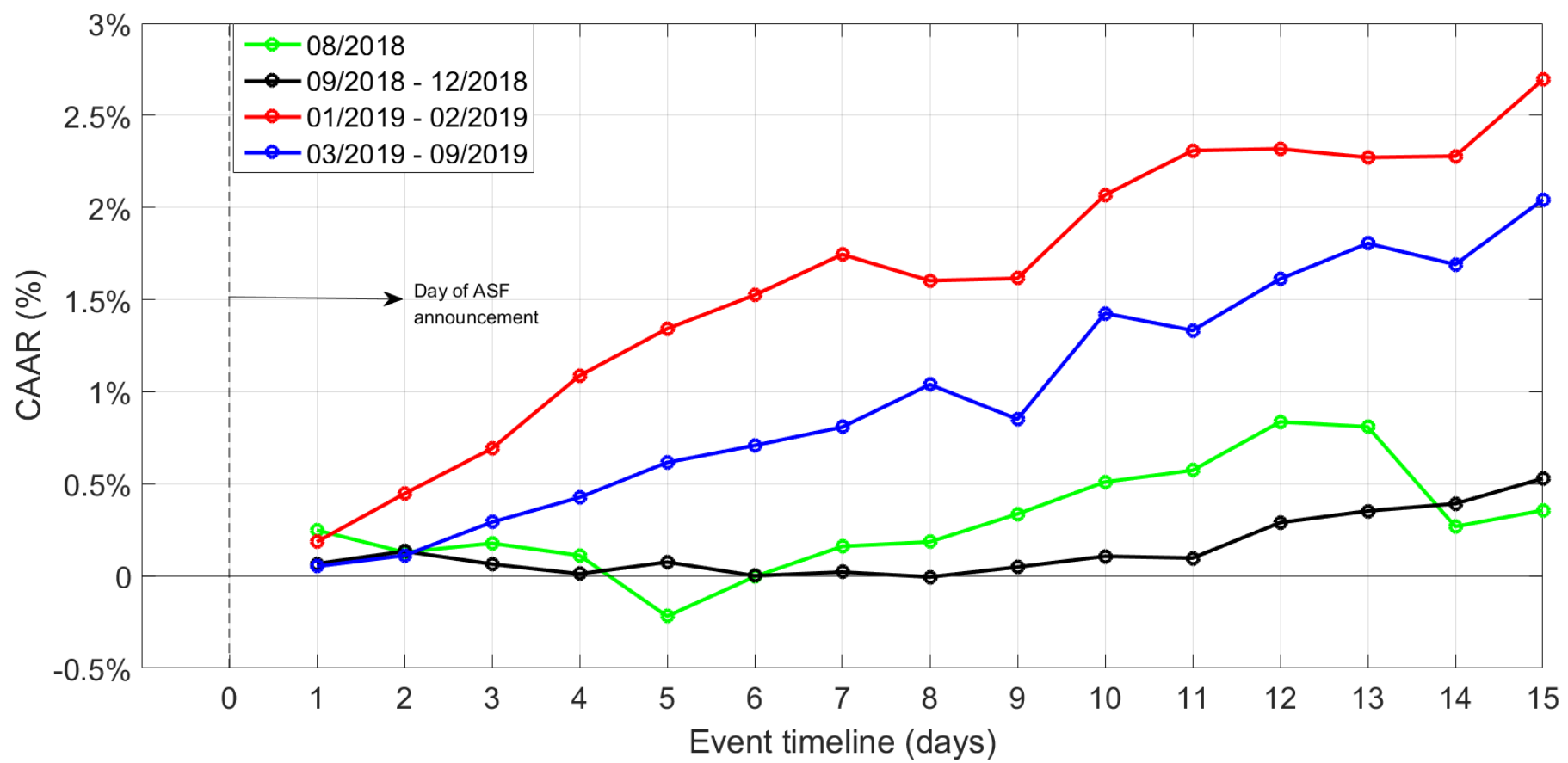

Figure 6: Cumulative average abnormal returns (CAAR) of foreign hog firms for all ASF announcements.

Notes: The vertical axis refers to CAAR values and the horizontal axis displays the event days since an ASF outbreak (at time 0). For each sub-sample period, every data point is a CAAR over a 1-day span, a 2-day span, and so on to a 15-day span since an ASF outbreak, respectively. The statistical significance of each CAAR is presented in Appendix Table A.3. 


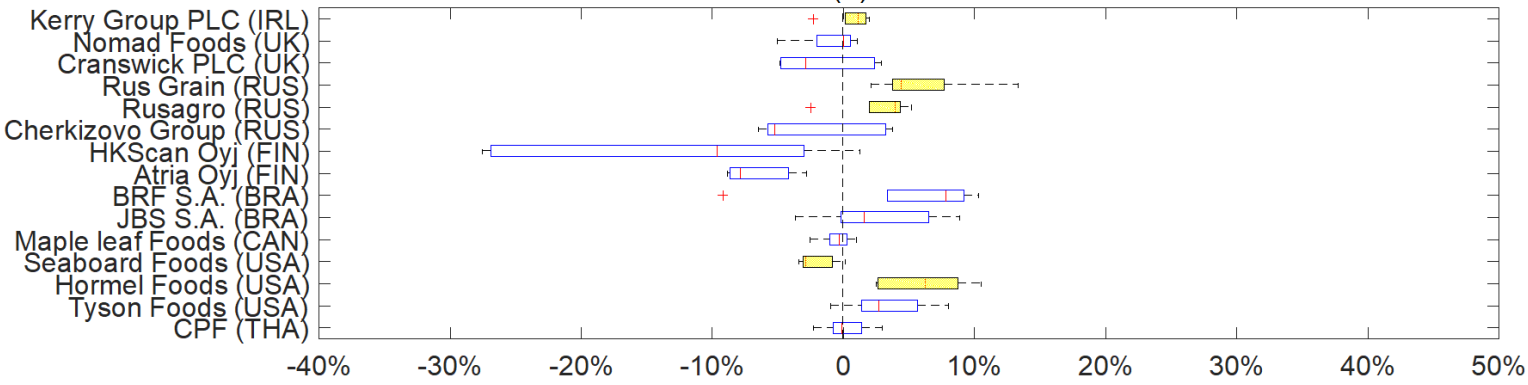

(b) $09 / 2018-12 / 2018$

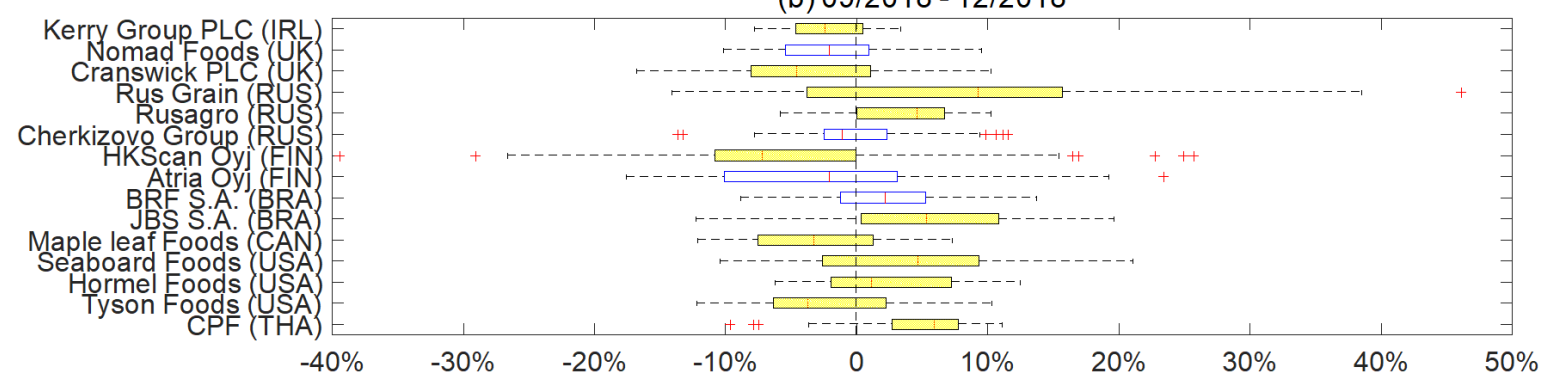

(c) $01 / 2019-02 / 2019$

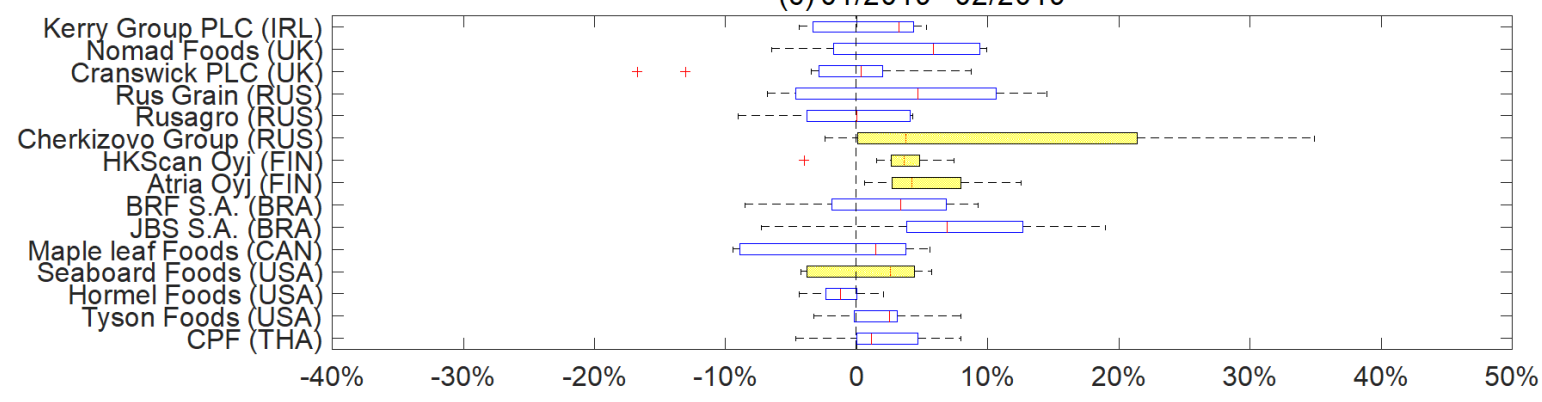

(d) $03 / 2019-09 / 2019$

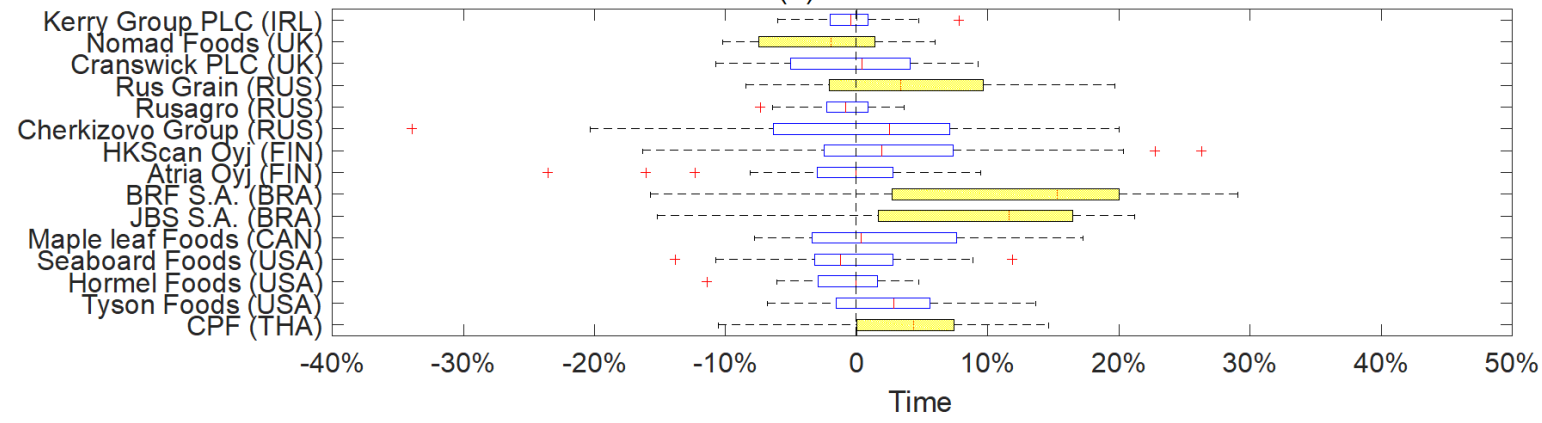

Figure 7: Cumulative abnormal returns (CAR) of foreign firms (a) in 08/2018, (b) from 09/2018 to $12 / 2018$, (c) from $01 / 2019$ to $02 / 2019$, (d) from $03 / 2019$ to $09 / 2019$.

Notes: In each figure, we present the distribution of firm-specific CAR values from all ASF events within each sub-sample period. CAR values are calculated by accumulating the abnormal returns from our event-study model for 15 trading days since each event $\left(\tau_{1}=1, \tau_{2}=15\right)$. The vertical axis displays 15 major foreign hog firms (in no particular order) and the horizontal axis is CAR values in percentage change (\%). Each box, moving from the left edge to the middle line and to the right edge is the 25 th percentile, median, and 75 th percentile of the distribution. Whiskers extending from the box connect the minimum and maximum CAR values. A box highlighted in yellow indicates that the average value is statistically different from zero from the adjusted BMP $t$-test under the significance level of $5 \%$, and is blank otherwise. Each + symbol in red indicates an outlier that is not included in the test sample. 
Table 1: Regressions of Cumulative Abnormal Returns for Chinese Hog Firms

\begin{tabular}{|c|c|c|c|c|c|}
\hline & Aug. 2018 & $\begin{array}{l}\text { Sept. } 2018 \\
\text { - Dec. } 2018 \\
\end{array}$ & $\begin{array}{l}\text { Jan. } 2019 \\
\text { - Feb. } 2019 \\
\end{array}$ & $\begin{array}{l}\text { Mar. } 2019 \\
\text { - Sept. } 2019 \\
\end{array}$ & $\begin{array}{l}\text { Aug. } 2018 \\
\text { — Sept. } 2019\end{array}$ \\
\hline Cumulative abnormal return ${ }_{t-1}$ & $\begin{array}{c}1.0554^{* * *} \\
(0.0118)\end{array}$ & $\begin{array}{c}0.9976^{* * *} \\
(0.0041)\end{array}$ & $\begin{array}{c}0.9125^{* * *} \\
(0.0148)\end{array}$ & $\begin{array}{c}0.9617^{* * *} \\
(0.0064)\end{array}$ & $\begin{array}{c}0.9759 * * * \\
(0.0036)\end{array}$ \\
\hline Trading volume & $\begin{array}{l}0.8411^{*} \\
(0.4717)\end{array}$ & $\begin{array}{c}0.5851^{* * *} \\
(0.0832)\end{array}$ & $\begin{array}{c}0.9145^{* * *} \\
(0.0936)\end{array}$ & $\begin{array}{c}0.4415^{* * *} \\
(0.0419)\end{array}$ & $\begin{array}{c}0.5300^{* * *} \\
(0.0351)\end{array}$ \\
\hline Trading volume $e_{t-1}$ & $\begin{array}{l}-0.6310 \\
(0.4828)\end{array}$ & $\begin{array}{c}0.2139^{* *} \\
(0.1027)\end{array}$ & $\begin{array}{c}-0.3544^{* * *} \\
(0.0993)\end{array}$ & $\begin{array}{c}-0.2285^{* * *} \\
(0.0430)\end{array}$ & $\begin{array}{c}-0.2820 * * * \\
(0.0357)\end{array}$ \\
\hline Baidu searching index & $\begin{array}{c}0.0071^{* * *} \\
(0.0019)\end{array}$ & $\begin{array}{l}0.0017^{*} \\
(0.0009)\end{array}$ & $\begin{array}{l}0.0121^{*} \\
(0.0062)\end{array}$ & $\begin{array}{c}0.0023 \\
(0.0050)\end{array}$ & $\begin{array}{c}0.0024^{* * *} \\
(0.0008)\end{array}$ \\
\hline Baidu searching index $x_{t-1}$ & $\begin{array}{c}-0.0042^{* *} \\
(0.0018)\end{array}$ & $\begin{array}{c}0.0028^{* * *} \\
(0.0009)\end{array}$ & $\begin{array}{c}-0.0385^{* * *} \\
(0.0061)\end{array}$ & $\begin{array}{c}0.0003 \\
(0.0050)\end{array}$ & $\begin{array}{c}0.0003 \\
(0.0008)\end{array}$ \\
\hline Feeder pig price & $\begin{array}{l}-0.0034 \\
(0.0164)\end{array}$ & $\begin{array}{l}-0.0013 \\
(0.0023)\end{array}$ & $\begin{array}{c}0.0231^{* * *} \\
(0.0030)\end{array}$ & $\begin{array}{c}0.0045^{* * *} \\
(0.0011)\end{array}$ & $\begin{array}{c}0.0077^{* * *} \\
(0.0010)\end{array}$ \\
\hline Feeder pig price t-1 $_{t}$ & $\begin{array}{l}-0.0049 \\
(0.0151)\end{array}$ & $\begin{array}{c}0.0017 \\
(0.0023)\end{array}$ & $\begin{array}{c}-0.0302^{* * *} \\
(0.0031)\end{array}$ & $\begin{array}{c}-0.0048^{* * *} \\
(0.0011)\end{array}$ & $\begin{array}{c}-0.0089^{* * *} \\
(0.0010)\end{array}$ \\
\hline Hog breeding and producing income share & $\begin{array}{l}0.0043^{*} \\
(0.0025)\end{array}$ & $\begin{array}{c}0.0007 \\
(0.0006)\end{array}$ & $\begin{array}{c}-0.0092^{* * *} \\
(0.0032)\end{array}$ & $\begin{array}{c}0.0007 \\
(0.0016)\end{array}$ & $\begin{array}{c}0.0009 \\
(0.0006)\end{array}$ \\
\hline Was the outbreak detected in large-size pig farm? & $\begin{array}{l}-0.0007 \\
(0.0020)\end{array}$ & $\begin{array}{l}-0.0007 \\
(0.0005)\end{array}$ & $\begin{array}{c}0.0028 \\
(0.0032)\end{array}$ & $\begin{array}{l}-0.0059 \\
(0.0037)\end{array}$ & $\begin{array}{c}-0.0014^{* *} \\
(0.0006)\end{array}$ \\
\hline The number of infected pigs & $\begin{array}{c}0.0022 \\
(0.0017)\end{array}$ & $\begin{array}{l}-0.0006 \\
(0.0004)\end{array}$ & $\begin{array}{c}0.0016 \\
(0.0017)\end{array}$ & $\begin{array}{l}0.0017^{*} \\
(0.0009)\end{array}$ & $\begin{array}{c}0.0003 \\
(0.0004)\end{array}$ \\
\hline Was the firm's pig farm in the same county as the outbreak? & $\begin{array}{l}-0.0001 \\
(0.0022)\end{array}$ & $\begin{array}{c}0.0016^{* *} \\
(0.0006)\end{array}$ & $\begin{array}{l}-0.0033 \\
(0.0030)\end{array}$ & $\begin{array}{l}0.0032^{*} \\
(0.0018)\end{array}$ & $\begin{array}{l}0.0016^{* *} \\
(0.0006)\end{array}$ \\
\hline Intercept & $\begin{array}{c}0.1619 \\
(0.2935)\end{array}$ & $\begin{array}{c}-0.0524^{* * * *} \\
(0.0074)\end{array}$ & $\begin{array}{c}0.3664^{* * *} \\
(0.0433)\end{array}$ & $\begin{array}{l}-0.0178^{*} \\
(0.0097)\end{array}$ & $\begin{array}{c}-0.0172^{* * *} \\
(0.0056)\end{array}$ \\
\hline Observations & 700 & 11900 & 1540 & 5180 & 19320 \\
\hline Adjusted $\mathrm{R}^{2}$ & 0.954 & 0.911 & 0.897 & 0.853 & 0.889 \\
\hline Number of firms & 10 & 10 & 10 & 10 & 10 \\
\hline ASF events & 5 & 85 & 11 & 37 & 138 \\
\hline Day dummies & Yes & Yes & Yes & Yes & Yes \\
\hline Month dummies & No & No & No & No & Yes \\
\hline Year dummies & No & No & No & No & Yes \\
\hline $\begin{array}{l}\text { Kao Test Statistics } \\
\text { Hadri LM Test Z Statistics }\end{array}$ & $\begin{array}{l}-7.9119 \\
-0.5256\end{array}$ & $\begin{array}{c}-32.3250 \\
0.0279\end{array}$ & $\begin{array}{l}-13.4389 \\
-0.2504\end{array}$ & $\begin{array}{l}-27.2926 \\
-3.9384\end{array}$ & $\begin{array}{l}-47.0227 \\
-1.8488\end{array}$ \\
\hline
\end{tabular}

Note: ${ }^{* * *} \mathrm{p}<0.01,{ }^{* *} \mathrm{p}<0.05,{ }^{*} \mathrm{p}<0.1$. In all regressions, the dependent variables are cumulative abnormal returns (CAR). CAR values in all regressions are calculated using a 15-day event window. Day dummies indicate days since each ASF event, from day 1 to day 15 . Kao test for panel cointegration uses the Augmented Dickey-Fuller t statistics with 1 lag, following the specifications in Equation (12); Hadri LM test for panel unit roots on residuals also includes 1 lag. Inference is based on clustered-robust standard errors (in parenthesis). 
Table 2: Regressions of Cumulative Abnormal Returns for Foreign Hog Firms

\begin{tabular}{|c|c|c|c|c|c|}
\hline & Aug. 2018 & $\begin{array}{l}\text { Sept. } 2018 \\
\text { - Dec. } 2018 \\
\end{array}$ & $\begin{array}{l}\text { Jan. } 2019 \\
\text { - Feb. } 2019 \\
\end{array}$ & $\begin{array}{l}\text { Mar. } 2019 \\
\text { — Sept. } 2019 \\
\end{array}$ & $\begin{array}{l}\text { Aug. } 2018 \\
\text { — Sept. } 2019 \\
\end{array}$ \\
\hline Cumulative abnormal return $_{t-1}$ & $\begin{array}{c}1.0159^{* * *} \\
(0.0148)\end{array}$ & $\begin{array}{c}0.9948^{* * *} \\
(0.0056)\end{array}$ & $\begin{array}{c}0.9587^{* * *} \\
(0.0134)\end{array}$ & $\begin{array}{c}1.0111^{* * *} \\
(0.0062)\end{array}$ & $\begin{array}{c}0.9951^{* * *} \\
(0.0041)\end{array}$ \\
\hline Trading volume & $\begin{array}{c}0.0377 \\
(0.4212)\end{array}$ & $\begin{array}{c}0.7796^{* * *} \\
(0.1675)\end{array}$ & $\begin{array}{c}0.0409 \\
(0.0704)\end{array}$ & $\begin{array}{l}0.2445^{*} \\
(0.1445)\end{array}$ & $\begin{array}{c}0.5916^{* * *} \\
(0.1563)\end{array}$ \\
\hline Trading volume $_{t-1}$ & $\begin{array}{c}0.3629 \\
(0.4697)\end{array}$ & $\begin{array}{l}-0.1995 \\
(0.1338)\end{array}$ & $\begin{array}{c}0.5367^{* * *} \\
(0.1772)\end{array}$ & $\begin{array}{l}0.3212^{* *} \\
(0.1401)\end{array}$ & $\begin{array}{l}-0.0112 \\
(0.1168)\end{array}$ \\
\hline Google searching index & $\begin{array}{c}2.86 \mathrm{E}-5 \\
(2.83 \mathrm{E}-5)\end{array}$ & $\begin{array}{c}-2.53 \mathrm{E}-5^{* * *} \\
(9.15 \mathrm{E}-6)\end{array}$ & $\begin{array}{l}-1.29 \mathrm{E}-5 \\
(2.36 \mathrm{E}-5)\end{array}$ & $\begin{array}{l}-7.81 \mathrm{E}-6 \\
(1.14 \mathrm{E}-5)\end{array}$ & $\begin{array}{c}-1.85 \mathrm{E}-5^{* * *} \\
(6.77 \mathrm{E}-6)\end{array}$ \\
\hline Google searching index ${ }_{t-1}$ & $\begin{array}{l}-2.28 \mathrm{E}-5 \\
(2.58 \mathrm{E}-5)\end{array}$ & $\begin{array}{c}-2.4 \mathrm{E}-5 * * * \\
(8.83 \mathrm{E}-6)\end{array}$ & $\begin{array}{l}-9.16 \mathrm{E}-6 \\
(2.58 \mathrm{E}-5)\end{array}$ & $\begin{array}{l}-2.1 \mathrm{E}-5^{*} \\
(1.15 \mathrm{E}-5)\end{array}$ & $\begin{array}{c}-2.33 \mathrm{E}-5^{* * *} \\
(6.61 \mathrm{E}-6)\end{array}$ \\
\hline The number of infected pigs & $\begin{array}{l}4.04 \mathrm{E}-6 \\
(0.0009)\end{array}$ & $\begin{array}{l}-0.0002 \\
(0.0003)\end{array}$ & $\begin{array}{c}0.0003 \\
(0.0005)\end{array}$ & $\begin{array}{c}0.0006 \\
(0.0004)\end{array}$ & $\begin{array}{l}-0.0001 \\
(0.0002)\end{array}$ \\
\hline Trading cost from exporters to China & $\begin{array}{l}-0.0001^{* *} \\
(2.29 \mathrm{E}-5)\end{array}$ & $\begin{array}{c}-4.65 \mathrm{E}-5^{* * *} \\
(1.18 \mathrm{E}-5)\end{array}$ & $\begin{array}{l}0.0001^{* * *} \\
(2.37 \mathrm{E}-5)\end{array}$ & $\begin{array}{c}4.52 \mathrm{E}-5^{* * *} \\
(1.39 \mathrm{E}-5)\end{array}$ & $\begin{array}{l}-1.6 \mathrm{E}-5 \\
(9.87 \mathrm{E}-6)\end{array}$ \\
\hline Intercept & $\begin{array}{c}0.0053 \\
(0.0040)\end{array}$ & $\begin{array}{c}0.0039^{* *} \\
(0.0016)\end{array}$ & $\begin{array}{c}-0.0054^{*} \\
(0.0032)\end{array}$ & $\begin{array}{c}-0.0061^{* * *} \\
(0.0019)\end{array}$ & $\begin{array}{c}0.0039^{* *} \\
(0.0016)\end{array}$ \\
\hline Observations & 983 & 14907 & 2015 & 6332 & 24237 \\
\hline Adjusted $\mathrm{R}^{2}$ & 0.899 & 0.897 & 0.840 & 0.913 & 0.898 \\
\hline Number of firms & 15 & 15 & 15 & 15 & 15 \\
\hline ASF events & 5 & 85 & 11 & 37 & 138 \\
\hline Day dummies & Yes & Yes & Yes & Yes & Yes \\
\hline Month dummies & No & No & No & No & Yes \\
\hline Year dummies & No & No & No & No & Yes \\
\hline $\begin{array}{l}\text { Kao Test Statistics } \\
\text { Hadri LM Test Z Statistics }\end{array}$ & $\begin{array}{r}-4.6772 \\
0.1924\end{array}$ & $\begin{array}{l}-26.8848 \\
0.0605\end{array}$ & $\begin{array}{c}-13.2969 \\
0.3058\end{array}$ & $\begin{array}{c}-18.7947 \\
0.2706\end{array}$ & $\begin{array}{c}-34.9042 \\
0.9391\end{array}$ \\
\hline
\end{tabular}

Note: ${ }^{* * *} \mathrm{p}<0.01,{ }^{* *} \mathrm{p}<0.05,{ }^{*} \mathrm{p}<0.1$. In all regressions, the dependent variables are cumulative abnormal returns (CAR). CAR values in all regressions are calculated using a 15-day event window. Day dummies indicate days since each ASF event, from day 1 to day 15. Kao test for panel cointegration uses the Augmented Dickey-Fuller t statistics with 1 lag, following the specifications in Equation (12); Hadri LM test for panel unit roots on residuals also includes 1 lag. Inference is based on clustered-robust standard errors (in parenthesis). 


\begin{abstract}
Online Appendix for
A Fortune from Misfortune: Evidence from Hog Firms' Stock Price Responses to China's African Swine Fever Outbreaks
\end{abstract}


Table A.1: Quarterly Percentage Changes in China's Hog Slaughter Numbers

\begin{tabular}{lc}
\hline Date & Percentage change in the number of slaughtered hogs (YoY) \\
\hline Q1 2018 & $4.36 \%$ \\
Q2 2018 & $3.11 \%$ \\
Q3 2018 & $0.72 \%$ \\
Q4 2018 & $-4.04 \%$ \\
Q1 2019 & $-5.70 \%$ \\
Q2 2019 & $-6.96 \%$ \\
Q3 2019 & $-40.38 \%$ \\
Q4 2019 & $-32.13 \%$ \\
\hline Source: The quarterly number of the slaughtered hog is from the National \\
Bureau of Statistics.
\end{tabular}

Table A.2: Monthly Percentage Declines in China's Hog and Sow Inventories

\begin{tabular}{lcc}
\hline Date & Percentage decline in hog inventory (YoY) & Percentage decline in sow inventory (YoY) \\
\hline $08 / 2018$ & $-2.4 \%$ & $-4.8 \%$ \\
$09 / 2018$ & $-1.8 \%$ & $-4.8 \%$ \\
$10 / 2018$ & $-1.8 \%$ & $-5.9 \%$ \\
$11 / 2018$ & $-2.9 \%$ & $-6.9 \%$ \\
$12 / 2018$ & $-4.8 \%$ & $-8.3 \%$ \\
$01 / 2019$ & $-12.6 \%$ & $-14.8 \%$ \\
$02 / 2019$ & $-16.6 \%$ & $-19.1 \%$ \\
$03 / 2019$ & $-18.8 \%$ & $-21 \%$ \\
$04 / 2019$ & $-20.8 \%$ & $-22.3 \%$ \\
$05 / 2019$ & $-22.9 \%$ & $-23.9 \%$ \\
$07 / 2019$ & $-25.8 \%$ & $-26.7 \%$ \\
$08 / 2019$ & $-32.2 \%$ & $-31.9 \%$ \\
$09 / 2019$ & $-38.7 \%$ & $-37.4 \%$ \\
\hline
\end{tabular}

Source: The percentage declines in both hog and sow inventories are from the Ministry of Agriculture and Rural Affairs. 


\section{The Adjusted BMP $t$-Test}

Boehmer et al. (1991) $t$-test is a widely used test statistic in event studies Kolari and

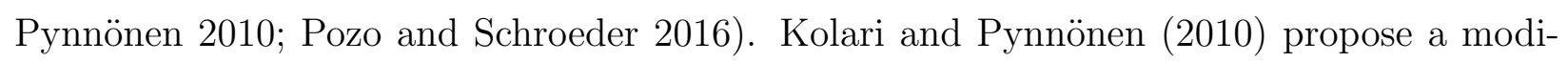
fication to the Boehmer et al. (1991) $t$-test (hereafter adjusted BMP $t$-test) to account for cross-correlation of the abnormal returns. Using the standardized abnormal returns and defining $\bar{r}$ as the average of the sample cross-correlation of the estimation period's abnormal returns, we construct the per period adjusted BMP $t$ statistic as:

$$
t_{A B, t}=t_{B, t} \sqrt{(1-\bar{r}) /(1+(N-1) \bar{r})},
$$

where $t_{A B, t}$ and $t_{B, t}$ are the adjusted and original BMP $t$ statistics, respectively. If the average return cross-correlation $\bar{r}$ is zero, the adjusted test statistic reduces to the original BMP $t$ statistic. Assuming the square-root rule holds for the standard deviation of different return periods, we can extend this test to measure the cumulative average abnormal returns $\left(H_{0}: C A A R=0\right)$ :

$$
t_{A B}=t_{B} \sqrt{(1-\bar{r}) /(1+(N-1) \bar{r})},
$$

where the new equation for the statistic remains unchanged, except that the subscript $t$ is now dropped. 
Table A.3: Adjusted BMP t-test Results for CAAR for Chinese and Foreign Hog Firms

\begin{tabular}{|c|c|c|c|c|c|c|c|c|}
\hline \multirow[b]{2}{*}{ Firm } & \multicolumn{2}{|c|}{$08 / 2018$} & \multicolumn{2}{|c|}{$09 / 2018-12 / 2018$} & \multicolumn{2}{|c|}{$01 / 2019-02 / 2019$} & \multicolumn{2}{|c|}{$03 / 2019-09 / 2019$} \\
\hline & CAAR & $t$ statistic & CAAR & $t$ statistic & CAAR & $t$ statistic & CAAR & $t$ statistic \\
\hline \multicolumn{9}{|l|}{ Chinese Firms } \\
\hline Wens Foodstuff & $7.86 \%$ & 0.952 & $6.90 \% * * *$ & 4.349 & $2.45 \%$ & -0.39 & $2.55 \%$ & 1.495 \\
\hline Muyuan Foodstuff & $-0.05 \%$ & -0.312 & $3.72 \% * * *$ & 2.742 & $3.17 \%$ & 0.114 & $3.59 \% *$ & 1.886 \\
\hline Zhengbang Tech. & $0.95 \%$ & -0.165 & $13.03 \% \%^{* * *}$ & 11.621 & $17.82 \% * * *$ & 4.896 & $2.31 \%$ & 0.742 \\
\hline Tech-Bank Food & $7.28 \%$ & 0.306 & $14.67 \% * * *$ & 9.501 & $19.95 \% * * *$ & 3.477 & $-3.33 \%$ & -1.018 \\
\hline New Hope Group & $-2.24 \%$ & -1.421 & $6.21 \%^{* * *}$ & 7.743 & $13.41 \% * * *$ & 2.934 & $5.05 \% * *$ & 2.137 \\
\hline Dabeinong Tech. & $-4.50 \% * * *$ & -2.620 & $1.27 \%$ & 1.209 & $11.57 \% * * *$ & 3.897 & $0.421 \%$ & 0.035 \\
\hline Tangrenshen Group & $-0.84 \%$ & -0.557 & $7.07 \% * * *$ & 7.817 & $24.77 \% * * *$ & 4.113 & $2.58 \%$ & 1.034 \\
\hline Tecon Animal Husbandry & $-12.56 \%$ *** & -5.954 & $1.56 \%$ & 0.393 & $17.94 \% * * *$ & 5.087 & $2.17 \%$ & 0.681 \\
\hline New Wellful & $-1.20 \%$ & -0.685 & $1.33 \%$ & 0.349 & $26.17 \%$ *** & 3.825 & $-0.07 \%$ & 0.393 \\
\hline Kingsino Tech. & $7.70 \% * *$ & 2.446 & $5.33 \%^{* * *}$ & 2.835 & $7.06 \%$ & 0.641 & $3.05 \%$ & 0.989 \\
\hline All Chinese Firms & $1.11 \%$ & -0.856 & $6.07 \% * * *$ & 7.877 & $15.82 \% \%^{* * *}$ & 5.622 & $2.58 \% *$ & 1.867 \\
\hline \multicolumn{9}{|l|}{ Foreign Firms } \\
\hline $\mathrm{CPF}$ & $0.24 \%$ & -0.499 & $4.73 \% * * *$ & 7.381 & $1.89 \% *$ & 1.688 & $3.21 \%^{* *}$ & 2.155 \\
\hline Tyson Foods & $3.34 \% *$ & 1.665 & $-2.19 \% * *$ & -2.159 & $1.82 \%$ & 1.445 & $2.61 \% *$ & 1.790 \\
\hline Hormel Foods & $6.02 \% * * *$ & 2.631 & $2.24 \% * * *$ & 3.124 & $-1.33 \%$ & -1.141 & $-0.69 \%$ & -1.058 \\
\hline Seaboard Foods & $-2.07 \% * * *$ & -3.092 & $3.40 \% * * *$ & 3.428 & $0.97 \% * *$ & 2.361 & $-0.63 \%$ & -1.067 \\
\hline Maple Leaf Foods & $-0.46 \%$ & -0.834 & $-3.02 \%^{* * *}$ & -3.205 & $-2.10 \%$ & -0.941 & $2.04 \%$ & 0.979 \\
\hline JBS S.A. & $2.71 \%$ & 1.483 & $5.50 \% * * *$ & 3.579 & $7.45 \% *$ & 1.812 & $7.59 \% * *$ & 2.332 \\
\hline BRF S.A. & $5.05 \%$ & 0.881 & $1.99 \% *$ & 1.857 & $2.352 \%$ & -0.547 & $11.40 \%$ *** & 2.953 \\
\hline Atria Oyj & $-4.83 \% *$ & -1.936 & $-2.27 \%^{*}$ & -1.681 & $5.01 \% * * *$ & 2.882 & $-1.12 \%$ & -0.951 \\
\hline HKScan Oyj & $-13.41 \%$ & -1.385 & $-5.78 \% * *$ & -2.398 & $3.37 \%^{* *}$ & 1.973 & $2.11 \%$ & 0.663 \\
\hline Cherkizovo Group & $-2.10 \%$ & -1.283 & $-0.08 \%$ & -0.563 & $11.92 \%$ ** & 2.304 & $0.13 \%$ & 0.139 \\
\hline Rusagro & $2.83 \% * * *$ & 5.290 & $3.87 \% * * *$ & 5.451 & $-0.72 \%$ & 0.227 & $-1.08 \% *$ & -1.678 \\
\hline Rus Grain & $5.99 \% * * *$ & 4.272 & $8.31 \% * * *$ & 3.167 & $3.23 \%$ & 0.797 & $4.36 \% * *$ & 2.022 \\
\hline Cranswick PLC & $-1.47 \%$ & -0.722 & $-3.90 \%{ }^{* * *}$ & -3.937 & $-1.47 \%$ & -0.248 & $-0.30 \%$ & 0.053 \\
\hline Nomad Foods & $-0.93 \% *$ & -1.822 & $-1.63 \%$ & -1.200 & $3.70 \%$ & 1.339 & $-2.51 \%^{* *}$ & -2.194 \\
\hline Kerry Group PLC & $0.67 \% * *$ & 2.034 & $-2.11 \%{ }^{* * *}$ & -4.282 & $1.03 \%$ & 0.626 & $-0.54 \%$ & -1.432 \\
\hline All Foreign Firms & $0.36 \%$ & 0.137 & $0.53 \%$ & -0.808 & $2.69 \% * * *$ & 3.574 & $2.04 \%$ ** & 2.389 \\
\hline
\end{tabular}

Note: ${ }^{* * *} \mathrm{p}<0.01,{ }^{* *} \mathrm{p}<0.05,{ }^{*} \mathrm{p}<0.1$. The top panel presents individual test results for each of the 10 Chinese hog firms and results for the average of all Chinese hog firms; the bottom panel presents individual test results for 15 foreign hog firms and results for the average of all foreign hog firms. All CAAR values are calculated from the accumulation over 15 post-event days $\left(\tau_{1}=1, \tau_{2}=15\right)$. 
Table A.4: Publicly Traded Firms Examined in This Study

\begin{tabular}{|c|c|c|c|}
\hline Ticker or Code & Firm & Stock Exchange (SE) & Country \\
\hline 300498 & Wens Foodstuff Group Co. Ltd. & Shenzhen SE (Second Board) & China \\
\hline 002714 & Muyuan Foods Co. Ltd. & Shenzhen SE (Small and Medium Enterprise Board) & China \\
\hline 002157 & Zhengbang Technology Co. Ltd. & Shenzhen SE (Small and Medium Enterprise Board) & China \\
\hline 002124 & Tech-bank Food Co. Ltd. & Shenzhen SE (Small and Medium Enterprise Board) & China \\
\hline 000876 & New Hope Group Co. Ltd. & Shenzhen SE (Main Board) & China \\
\hline 002385 & Dabeinong Technology Group Co. Ltd. & Shenzhen SE (Small and Medium Enterprise Board) & China \\
\hline 002567 & Tangrenshen Group Co. Ltd. & Shenzhen SE (Small and Medium Enterprise Board) & China \\
\hline 002100 & Tecon Animal Husbandry Co. Ltd. & Shenzhen SE (Small and Medium Enterprise Board) & China \\
\hline 600975 & New Wellful Co. Ltd. & Shanghai SE & China \\
\hline 002548 & Kingsino Technology Co. Ltd. & Shenzhen SE (Small and Medium Enterprise Board) & China \\
\hline $\mathrm{CPF}$ & Charoen Pokphand Foods Public Co. Ltd. & Bangkok SE & Thailand \\
\hline TSN & Tyson Foods Inc. & New York SE & USA \\
\hline HRL & Hormel Foods Corp. & New York SE & USA \\
\hline SEB & Seaboard Foods Corp. & New York SE & USA \\
\hline MLFNF & Maple Leaf Foods Inc. & Toronto SE & Canada \\
\hline JBSAY & JBS S A/S ADR & OTC Markets & Brazil \\
\hline BRFS & BRF S.A. & New York SE & Brazil \\
\hline ATRAV & Atria Oyj & Helsinki SE & Finland \\
\hline HKSAV & HKScan Corp. & Helsinki SE & Finland \\
\hline GCHE & Gruppa Cherkizovo PAO & Moscow Exchange & Russia \\
\hline AGRO & Ros Agro PLC & Moscow Exchange & Russia \\
\hline RUGR & Rusgrain Holding PAO & Moscow Exchange & Russia \\
\hline CWK & Cranswick PLC & London SE & UK \\
\hline NOMD & Nomad Foods Ltd. & New York SE & UK \\
\hline KYGA & Kerry Group PLC & London SE & Ireland \\
\hline
\end{tabular}


(a) CAR of USA companies

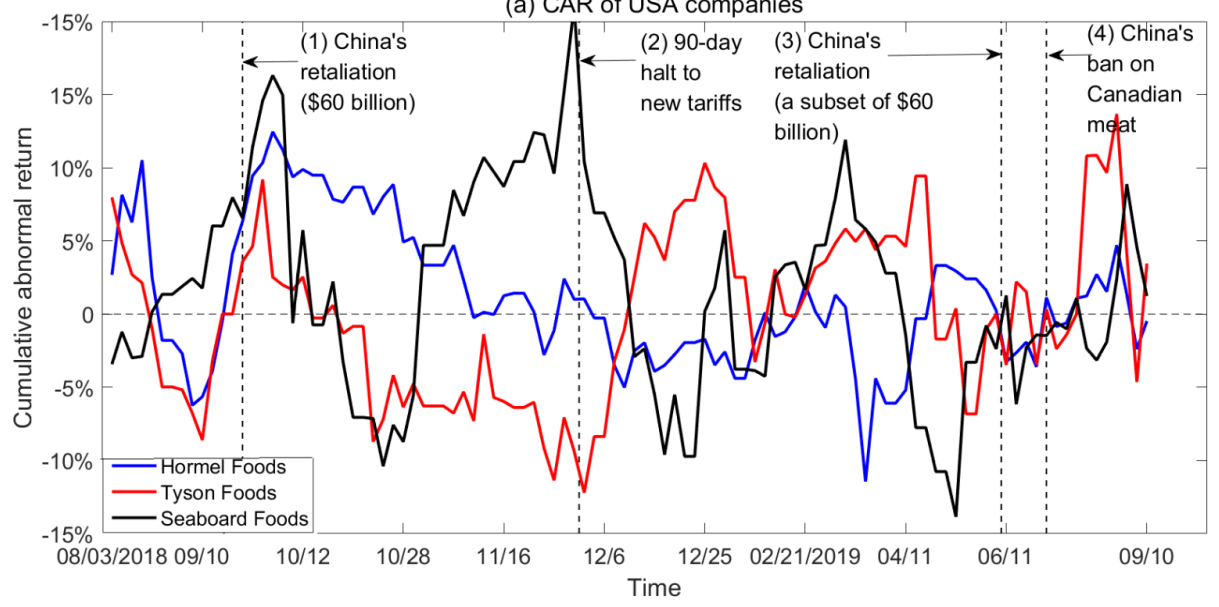

(b) CAR of Canadian company
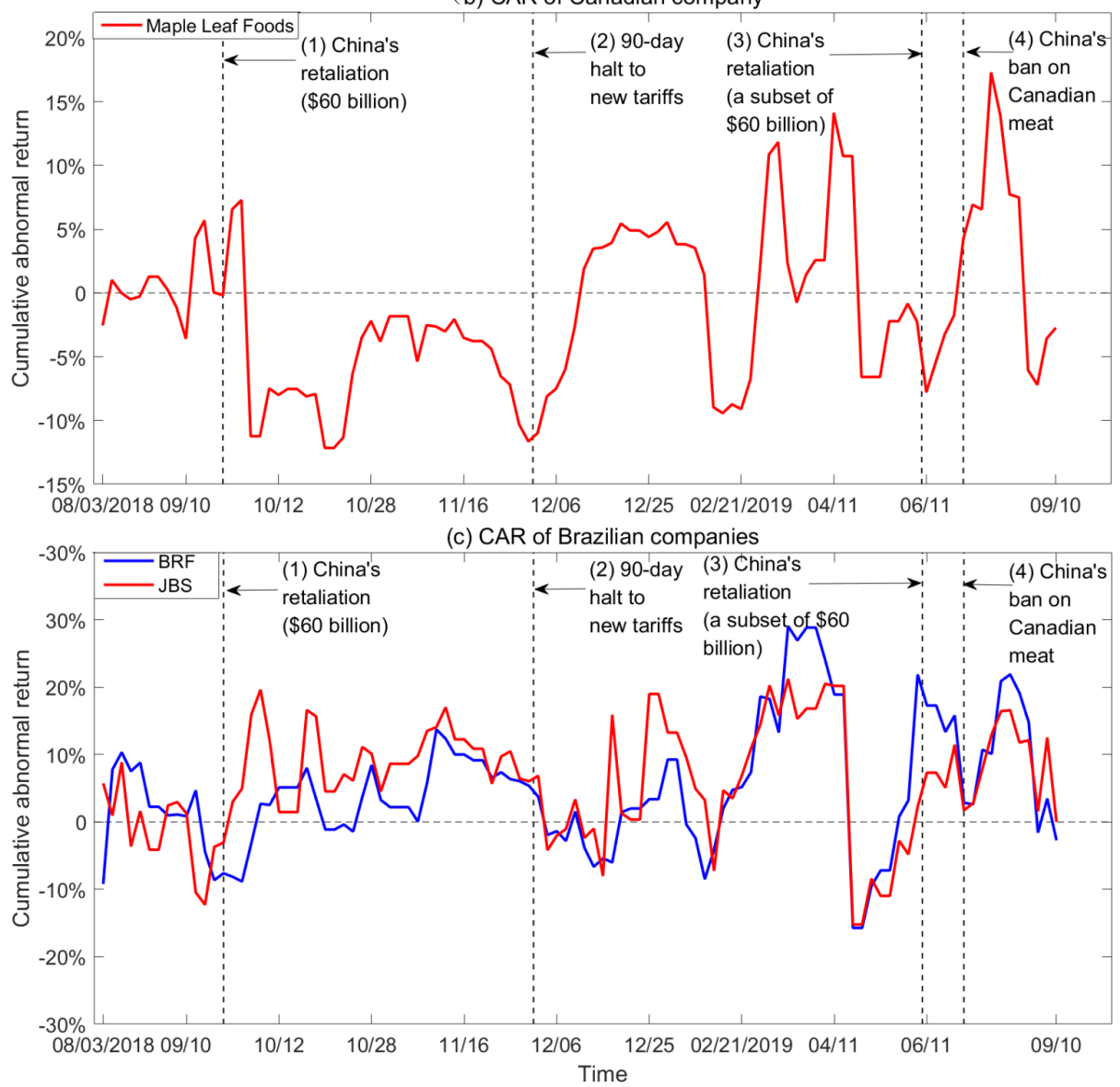

Figure A.1: Cumulative abnormal returns (CAR) of U.S. (top), Canadian (middle), and Brazilian (bottom) firms with four important events in the U.S.-China trade war.

Notes: For each panel, moving from left to right, the vertical short-dashed lines indicate: $(a)$ On September 24, 2018, China responded to U.S. tariffs (US\$200 billion worth of Chinese goods) with retaliatory tariffs on US\$60 billion worth of U.S. goods; (b) On December 1, 2018, the U.S. and China agreed to refrain from increasing tariffs or imposing new tariffs for 90 days during the G20 Summit; (c) On June 1, 2019, China increased tariffs imposed on about $\$ 60$ billion of U.S. goods (a subset of $\$ 60$ billion) in retaliation for the Trump administration's latest decision to increase duties on $\$ 200$ billion worth of Chinese goods; and, $(d)$ in the middle of the Huawei dispute between Canada and China, China halted all meat imports from Canada over "forged pork certificates" on June 26, 2019. 